NBER WORKING PAPER SERIES

\title{
THE SIZE AND SCOPE OF GOVERNMENT: COMPARATIVE POLITICS WITH \\ RATIONAL POLITICIANS
}

\author{
Torsten Persson \\ Guido Tabellini
}

Working Paper 6848

http://www.nber.org/papers/w6848

\author{
NATIONAL BUREAU OF ECONOMIC RESEARCH \\ 1050 Massachusetts Avenue \\ Cambridge, MA 02138 \\ December 1998
}

1998 Alfred Marshall Lecture, delivered on September 5 at the EEA Congress in Berlin. The underlying research is supported by the European Commission (a TMR grant), by the Bank of Sweden Tercentenary Foundation, and by Bocconi University. We are grateful to Michele Polo and Gerard Roland for several conversations on the topic of this lecture, to Michael Castaneira, John Faust, Per Krusell, and Lars Svensson for helpful comments on a previous version, to Giovanni Favara, Jesper Roine, and Marcus Salomonsson for research assistance and to Christina Lönnblad for editorial assistance. The views expressed here are those of the author and do not reflect those of the National Bureau of Economic Research.

(C) 1998 by Torsten Persson and Guido Tabellini. All rights reserved. Short sections of text, not to exceed two paragraphs, may be quoted without explicit permission provided that full credit, including $\mathbb{C}$ notice, is given to the source. 
The Size and Scope of Government:

Comparative Politics with Rational Politicians

Torsten Persson and Guido Tabellini

NBER Working Paper No. 6848

December 1998

JEL No. D7, E6, H1, H4

\section{ABSTRACT}

We try to demonstrate how economists may engage in research on comparative politics, relating the size and composition of government spending to the political system. A Downsian model of electoral competition and forward-looking voting indicates that majoritarian -- as opposed to proportional -- elections increase competition between parties by focusing it into some key marginal districts. This leads to less public goods, less rents for politicians, more redistribution and larger government. A model of legislative bargaining and backward-looking voting indicates that presidential -- as opposed to parliamentary -- regimes increase competition between both politicians and voters. This leads to less public goods, less rents for politicians, less redistribution, and smaller government. We confront these predictions with cross-country data from around 1990, controlling for economic and social determinants of government spending. We find strong and robust support for the prediction that the size of government is smaller under presidential regimes, and weaker support for the prediction that majoritarian elections are associated with less public goods.

Torsten Persson

Institute for International Economic Studies

Stockholm University

S-10691 Stockholm

SWEDEN

and NBER

Torsten.Persson@iies.su.se
Guido Tabellini

IGIER

Bocconi University

via Salasco 3/5

20136 Milan

ITALY

guido.tabellini@uni-bocconi.it 


\section{Introduction}

Looking across the countries of the world, we observe a wide variation in the size of government and in the scope of its activities. The white bars in Graph 1 depict total central government expenditures for a number of democratic countries. The data are expressed as a share of GDP and averaged over 1988-92. Countries are grouped by development level - OECD membership, or not - and, among developing countries, by continent. Within groups they are ordered by IMF codes. Evidently, expenditures vary a great deal, both within and between groups. Much of this variation reflects differences in socio-economic determinants of government expenditure. But large differences remain, even when we control for economic and social variables suggested by economic theory and found to have explanatory power in previous empirical studies. The black bars in the graph show the residuals from a regression of expenditures on (the log of) per capita income, (the log of) openness to international trade, the share of population above 65 , and a measure of ethno-linguistic fractionalization. The controls account for a substantial share of the variation (about 60 per cent), and the differences across groups of countries more or less disappear. But striking differences within groups remain, and residuals of plus or minus $10 \%$ of GDP are not uncommon. The results are very similar if the set of controls is expanded to include other determinants of spending. ${ }^{1}$

\section{Insert Graph 1 about here}

We observe a similar degree of variation in the scope of government. Graph 2 is constructed in the same way as Graph 1. But it illustrates the cross-country variation for a measure of spending on public goods, namely the sum of spending on transportation, education and order and safety. This variable also refers to central government, and it is expressed as a share of GDP on average between 1988-92. The controls used to generate the residuals are the same, except that fractionalization is replaced by a measure of centralization in total government spending. Again, the differences and the residual variation are striking.

\footnotetext{
${ }^{1}$ Section 5 discusses the data, the sample of countries, and alternative specifications at more length.
} 


\section{Insert Graph 2 about here}

How can we explain this variation? There are many possible, and complementary, answers to this question. In this lecture, we advocate building a positive theory of the size and scope of government on the basis of comparative politics. That is, we ask whether and how different political institutions affect the size and composition of government spending. In particular, we study two fundamental features of political institutions: the electoral rule, contrasting majoritarian and proportional electoral systems, and the regime type, contrasting presidential and parliamentary regimes.

Despite a large literature on the size of government, the specific question of how these political institutions influence public spending has been neglected until recently. Traditional public finance, with its normative approach, has not even posed the question. The literature on public choice and political economics has provided important insights on the determinants of the size of governmentdifferent branches of this literature are surveyed in Frey (1983), Mueller (1989), Mueller (1997) and Persson and Tabellini (1998). But most of this research has not systematically investigated the link between political institutions and public spending, and to the extent that it has, the focus has been on features other than the electoral rule and the regime type. ${ }^{2}$

Political scientists have done much more work comparing political systems, and comparative politics is indeed a well-established subfield in political science. A large body of theoretical, empirical and descriptive research concentrates precisely on electoral rules and regime types. But this work is typically confined to the analysis of political phenomena, such as how the electoral rule affects the number of parties, or how the regime type affects the frequency of political crises, or protests by the citizens. ${ }^{3}$

\footnotetext{
${ }^{2}$ Von Hagen and Harden (1996), Alesina and Perotti (1996), and Inter-American Development Bank (1997) contrast alternative budgetary institutions, but their main focus is on budget deficits, not on the size or composition of spending. Roubini and Sachs (1989) and Grilli, Masciandaro and Tabellini (1991) discuss electoral rules and party structures of OECD countries, but again with regard to public debt accumulation. There is a also a literature on fiscal federalism and the size of government, which is surveyed in Inman and Rubinfeld (1997) and Persson and Tabellini (1998). Finally a small but interesting literature discusses how direct democracy shapes the size of government (see for instance Pommerehne and Frey (1978)).

${ }^{3}$ Recent classics on comparative politics include Bingham Powell (1982), Lijphart (1984), Taagepera and Shugart (1989), Shugart and Carey (1992), and Cox (1997). Myerson (1998) also discusses this literature.
} 
In this lecture, we try to exemplify how economists may pursue an approach of comparative politics. Like the political scientists, we focus on electoral rules and regime types. But we go beyond the political system, using simple theory to derive specific hypotheses regarding policy choice. We then take some of these hypotheses to the data.

We start by formulating (in Section 2) a simple model of public finance. Elected politicians can tax the voters and choose how to allocate the revenue among three alternative uses: to rents benefiting themselves, to a public good benefiting all the voters, or to redistributive transfers benefiting a more narrow group of voters.

Two central assumptions are that politicians are self-interested, and that voters are rational and fully informed. In particular, politicians would like to raise a lot of revenue and spend it on rents for themselves. This view of politics may strike some readers as too cynical. But we think it is a useful methodological approach, since it poses the right questions: What makes politicians behave in the interest of voters? And how does this depend on political institutions? Of course, we are not the first to address these questions. A common opinion is the so called "Chicago view", that political competition between selfish politicians leads to the implementation of efficient policies. ${ }^{4}$

An important theme of our lecture is that this view of the political process is too optimistic. Even with fully informed voters, political equilibria typically exhibit two political failures. First, public goods are under-provided because of redistributive transfers to powerful groups of voters. Intuitively, politicians neglect the interests of some voters, as they only need to please a subset of the voters to win the elections. Second, politicians earn positive rents for themselves, at the voters expense. Intuitively, politicians enjoy considerable discretion once in office, because electoral promises are only verifiable or enforceable in some dimensions of policy. What a politician does, once in office, will therefore not only reflect his electoral promises, but also his view of the world. As competing politicians differ in their ideologies or along other important dimensions, they remain imperfect substitutes. Because of this imperfect substitutability, rents are not fully dissipated in the course of electoral competition.

Another important theme of our lecture is that the extent of these political failures depends on political institutions. Intuitively, both the electoral rule and the regime type determine the scope and the intensity of political competition. In general, those regimes that promote more intense competition imply policy choices

\footnotetext{
${ }^{4}$ See in particular Stigler (1972), Wittman (1989).
} 
that internalize the benefits and costs of fewer voters. Those regimes therefore bring about less public good provision. But more competition also brings about smaller rents for the politicians.

We develop these ideas in two different models of political behavior. In Section 3 , we study a traditional Downsian model of two-candidate electoral competition. We label it pre-election politics, because all the action takes place before the elections. The model assumes that politicians can make binding commitments to policy platforms ahead of the election. Forward-looking voters then choose the policy platform most favorable to them. In this setting, we ask how the electoral rule influences policy choices, contrasting majoritarian and proportional elections. The central difference is that majoritarian elections make politicians concentrate their competition for votes in certain "marginal" electoral districts. Typically, these districts consist of more mobile voters, who can be more easily swayed by electoral promises. Hence, electoral competition is stiffer under majoritarian elections, as politicians try to please "swing voters" in the marginal districts, rather than swing voters in the population as a whole. Among other things, this leads to more targeted redistribution, at the expense of public good provision. The results in this section draw on earlier insights by Lindbeck and Weibull (1987), Svensson (1997), Lizzeri and Persico (1998), and Polo (1998).

In Section 4, we turn to a very different model of political behavior. We label it post-election politics, as we drop the unrealistic assumption of binding commitments ahead of the election. Here, incumbent politicians set policy once they are in office. And elections serve the purpose of holding these politicians accountable to backward-looking voters. This setting is appropriate for doing comparative politics on a different set of institutions, namely those that allocate decision-making authority. The political constitution is thus viewed as an "incomplete contract", specifying who has the right to propose, veto, or amend policy, and in which dimensions. In this setting, we contrast two regime types, presidential and parliamentary. The central insight is that a presidential system entails stiffer competition between different voters, as well as between different politicians. Politicians compete more fiercely among themselves because they are held directly and separately accountable by the voters. Compared to a Parliamentary regime, this limits the scope of collusion. As coalitions among politicians are more unstable, voters end up competing more fiercely for the redistributive transfers than in a parliamentary regime. These features imply less spending on every budget item in presidential regimes and, hence, to a smaller size of government. The results in this section were originally derived in a series of joint papers 
with Gerard Roland (Persson, Roland and Tabellini (1997), (1998a), (1998b)).

In Section 5, we then confront the specific hypotheses generated by these two models with cross-country data. Using the theory, we classify the democracies in our sample according to their electoral rule and regime type. On the whole, the empirical results are very encouraging. We find strong and robust evidence that, ceteris paribus, governments are indeed smaller in presidential regimes as the theory suggests. We also find some support for the hypothesis that majoritarian elections are associated with lower supply of public goods.

Section 6 ends with some remarks on where to go next.

\section{A public finance model}

Consider a society with three distinct groups of voters, denoted by $i=1,2,3$. Each group has a continuum of voters with unit mass. The preferences over government policy are identical for every member of group $i$ and given by the quasi-linear utility function:

$$
w^{i}=c^{i}+H(g)=1-t+b^{i}+H(g) .
$$

Here, $c^{i}$ is private consumption of group $i, t$ is a common tax rate, $b^{i}$ is a transfer payment to group $i$, and $g$ is the supply of (Samuelsonian) public goods, evaluated by the concave and monotonically increasing function $H(g)$. Thus, we assume that income gross of taxes is equal to one for all individuals, that taxes are nondistorting and that the tax rate is the same for every group.

The public policy vector $q$ is defined by:

$$
q=\left[t, g, r,\left\{b^{i}\right\}\right] \geq 0,
$$

where all components are constrained to be non-negative. Any feasible policy must satisfy the government-balanced budget constraint:

$$
3 t=\sum_{i} b^{i}+g+r .
$$

The component $r$ reflects (endogenous) "rents" to politicians and it is a deliberate object of choice. As discussed in Persson, Roland and Tabellini (1997), we can think of $r$ as an outright diversion of resources, such as corruption or party financing, or more generally as an allocation of resources that benefits the private 
agenda of the politicians but appears as an inefficiency for the voters. ${ }^{5}$ When an assembly of elected politicians take the policy decisions (as in Section 4), these diversions may benefit some politicians more than others, in which case $r$ must be disaggregated. We assume diversions to be associated with some transaction costs $(1-\gamma)$, such that only $\gamma r$ benefit the politicians. From the voters' viewpoint, however, these rents constitute pure waste. Thus, not only do we assume politicians to be selfish, but we also assume them to have an opportunity to take advantage of their power. Naturally, equilibrium rents could be very small. But the aspiration of politicians to extract these rents may still shape their decisions in other policy dimensions.

To make the public finance problem more interesting, we could extend the model with a labor supply choice distorted by taxation. Below, we comment on how our results would change in this richer formulation. But even this simple model entails a very rich micro-political problem. There are three conflicts of interest: between different voters (over the allocation of redistributive transfers, $\left\{b^{i}\right\}$ ), between voters and politicians (over the size of rents, $r$ ), and between different politicians (over the distribution of these rents among themselves). As we shall see, different political systems alter the scope and intensity of these conflicts, basically by inducing more or less competition between politicians or voters.

\section{Pre-election politics}

In this section, we consider the solution of our policy problem from a traditional angle, namely as the outcome of Downsian electoral competition. Two officemotivated candidates make binding commitments to policy platforms in the election campaign, and rational voters select the policy platform most favorable to them. In formulating this model, we draw on the insights of several earlier contributions. As in Lindbeck and Weibull's (1987) work on redistribution, we use a model with probabilistic voting to handle electoral equilibrium when policy is inherently multi-dimensional. ${ }^{6}$ As in Myerson (1993), Grillo and Polo (1993),

\footnotetext{
${ }^{5}$ Svensson (1997) analyzes a more elaborate model where inefficiencies arise as high costs for public projects. These inefficiencies benefit bureaucrats in the public administration who, in turn, are monitored more or less tightly by the politicians.

${ }^{6}$ Lindbeck and Weibull (1987), in turn, build on probabilistic voting models by Hinich, Ledyard and Ordershook (1972) and by Coughlin and Nitzan (1981), among others. See also our survey, Persson and Tabellini (1998).
} 
Svensson (1997) and Polo (1998), we allow for endogenous rents in addition to the traditional assumption of pure office motivation. And as in Lizzeri and Persico's (1998) study of redistribution versus public goods, we use our model to investigate different electoral incentives.

Already at the outset, we want to emphasize that our model - at bestcaptures only one of several possible effects of different electoral systems. In particular, we hold the party structure fixed, ignoring theoretical arguments as well as empirical evidence for a larger number of parties under proportional elections. Our excuse is pragmatic; we simply do not know how to analyze multi-dimensional policy consequences of electoral competition in a multi-party setting.

\subsection{General features}

Consider two parties or candidates, labeled $A$ and $B$. Before elections take place, these parties commit to policy platforms, $q^{A}$ and $q^{B}$. They act simultaneously and do not cooperate. The platform of the winning party is implemented. As we emphasize below, the precise conditions for winning depend on the electoral rule. Consider, say, party $A$. When announcing its policy platform, it maximizes the expected value of rents, namely:

$$
E\left(u^{A}\right)=p^{A} \cdot(R+\gamma r),
$$

where $R$ denotes the (exogenous) "ego rents" associated with winning the elections, and $p^{A}$ denotes the (endogenous) probability that $A$ wins, given $q^{A}$ and $q^{B}$.

Why is the election outcome uncertain, when platforms are chosen? We assume that the two parties are intrinsically different in some dimension other than the announced policies. One can think of these intrinsic differences as reflecting "ideologies" or, the personal features of leading party candidates. Thus, we are implicitly assuming that parties cannot really make binding commitments over all policy dimensions, so that some aspects of their future behavior will reflect their intrinsic features. Voters evaluate ideology in different ways. Specifically, let $W^{i}(q)$ denote the preferences of voters in group $i$ over government policy. That is, $W^{i}(q)$ is the indirect utility obtained by substitution of (2.2) into (2.1). Then voter $j$ in group $i$ votes for party $A$ if

$$
W^{i}\left(q^{A}\right)>W^{i}\left(q^{B}\right)+\left(\delta+\sigma^{j}\right),
$$


where the term $\left(\delta+\sigma^{j}\right) \lesseqgtr 0$, reflects voter $j^{\prime}$ s ideological preference for party $B$. This term includes two components; $\sigma$ is common to all voters and $\sigma^{j}$ idiosyncratic.

We can think of $\delta$ as the general popularity of party $B$. We assume that $\delta$ is a random variable with a uniform distribution on $\left[-\frac{1}{2 d}, \frac{1}{2 d}\right]$. Thus, the density of this distribution is given by $d$ and the expected value of $\delta$ is zero. Furthermore, $\delta$ is realized between the announcement of the party platforms and the election. This assumption means that parties announce their platforms under uncertainty about the election outcome. Clearly, such uncertainty is very plausible. It is also technically convenient; as we shall see below, it smooths the optimization problem facing the parties.

The variable $\sigma^{j}$ reflects the individual ideology of voter $j$. The distribution of $\sigma^{j}$ differs across groups. These distributions are uniform on $\left[-\frac{1}{2 s^{i}}+\bar{\sigma}^{i}, \frac{1}{2 s^{i}}+\bar{\sigma}^{i}\right]$, $i=1,2,3$. They are fully characterized by two parameters, $\bar{\sigma}^{i}$ and $s^{i}$, and groups differ over both. In other words, groups differ in their average ideology, captured by the group-specific means $\bar{\sigma}^{i}$. But they also differ in their ideological homogeneity, a higher density $s^{i}$ being associated with a more narrow distribution of $\sigma^{j}$. We make specific assumptions about these differences in distribution. Suppose we label the three groups according to their average ideology $\bar{\sigma}^{i}: \bar{\sigma}^{1}<\bar{\sigma}^{2}<\bar{\sigma}^{3}$. Then, we assume that group 2 also has the highest density: $s^{2}>s^{1}, s^{3}$. This is the substantial assumption. For convenience, we also assume that $\bar{\sigma}^{2}=0$ and that $\bar{\sigma}^{1} s^{1}+\bar{\sigma}^{3} s^{3}=0 .^{7}$

The meaning of these assumptions is illustrated in Figure 1, where we have drawn the distributions for $\sigma^{j}$ in the three groups. Each of the three groups has an "ideologically neutral" voter with $\sigma^{j}=0$, and the further to the right we go in the figure, the more likely we are to find a voter who will vote for party $B$. Assume, for concreteness, that $\delta=0$ and, furthermore, that the two candidates have announced the same policies $q^{A}=q^{B}$. In this event, the ideologically neutral voters with $\sigma^{j}=0$ in each group are indifferent between the two candidates. We label these indifferent voters "swing voters". Every voter with $\sigma^{j}$ below (above) 0 finds it optimal to vote for party $A$ (party $B) .{ }^{8}$ As the figure illustrates, our

\footnotetext{
${ }^{7}$ We assume that the parties know these group-specific distributions when they announce their policy and that the electoral uncertainty derives entirely from uncertainty about the common component, $\delta$. Alternatively, we could have generated the uncertainty by doing away with $\delta$ and instead assume the group means $\bar{\sigma}^{i}$ to be random.

${ }^{8} \mathrm{We}$ assume that a swing voter, being indifferent between the parties, tosses a coin when deciding how to vote.
} 
assumptions imply that the group which on average is ideologically neutral also has the largest number of ideologically neutral voters. ${ }^{9}$ It is natural to think of this group as consisting of "middle class" voters.

\section{Insert Figure 1 about here}

We can also use this figure to illustrate how the parties evaluate the announcement of different policies. Suppose party $A$ contemplates a deviation from a common policy announcement $q^{A}=q^{B}$. Such a deviation alters the number of votes party $A$ can expect, by changing the identity of the swing voters. For example, a lower tax rate $t$ or more public goods $g$ benefit voters in all groups symmetrically. Taken separately, such measures thus push the identity of the swing voter in all groups to the right by the same distance, say to $\sigma^{\prime}$, and party $A$ can expect to capture the voters between 0 and $\sigma^{\prime}$ in all groups (as the expected value of $\delta$ is equal to zero). Similarly, more transfers to group 1, financed by less transfers to group 3 , shift the swing voter in group 1 to the right and the swing voter in group 3 to the left by the same distance (recall that we assume the groups to have the same size). This redistribution implies a net gain in votes, as there are more swing voters in group 1 than in group 3; that is, $s^{1}>s^{3}$. Finally, higher rents $r$ mean losing votes in all three groups, and a lower probability of winning. As the announced policies must respect the budget constraint, the two parties effectively trade off votes for votes, or rents for votes, when designing their platforms.

As a final preliminary, we define $\pi^{A, i}$, the vote share of party $A$ in group $i$. Given our assumptions about the group-specific distributions, $\pi^{A, i}$ can be expressed as:

$$
\pi^{A, i}=s^{i}\left[W^{i}\left(q^{A}\right)-W^{i}\left(q^{B}\right)-\delta-\bar{\sigma}^{i}\right]+\frac{1}{2},
$$

where the expression within square brackets is a formal definition of the swing voter in group $i$. Clearly, the vote share of party $B$ in group $i$ is given by $1-$ $\pi^{A, i}$. Note that, from the point of view of both candidates, $\pi^{A, i}$ is a random variable, since it is a transformation of the random variable $\delta$ capturing the average popularity of party $B$.

\footnotetext{
${ }^{9}$ We will sometimes find it more convenient to talk about the number of voters instead of the density, even though we are formally assuming that the distributions are continuous.
} 


\subsection{Proportional elections}

We first use our model of pre-electoral politics to study policy outcomes under an electoral rule corresponding to proportional representation. Specifically, we study a very stylized case where (as in the Netherlands) there is only one voting district, comprising all the voters in the population. Winning the election thus corresponds to obtaining more than $50 \%$ of the total vote. Under this electoral rule, $p^{A}$ is given by:

$$
p^{A}=\operatorname{Prob}\left[\frac{1}{3} \sum_{i} \pi^{A, i} \geq \frac{1}{2}\right]
$$

where the probability refers to the random variable $\delta$. By (3.3) and our previous assumption that $\delta$ has a uniform distribution, we have:

$$
p^{A}=\frac{d}{3 s} \sum_{i}\left[s^{i}\left(W^{i}\left(q^{A}\right)-W^{i}\left(q^{B}\right)\right)\right]+\frac{1}{2},
$$

where $s \equiv \sum_{i} s^{i} / 3$ is the average density across groups. By symmetry, party $B^{\prime} \mathrm{s}$ probability of winning is $\left(1-p^{A}\right)$.

Given our distributional assumptions and the concavity of $H(g)$, a unique equilibrium exists. One immediate feature of this equilibrium is that both $A$ and $B$ choose the same policy. Formally, they face the same maximization problems, as $p^{B}=\left(1-p^{A}\right)$ and as $q^{A}$ and $q^{B}$ enter (3.5) symmetrically, but with opposite signs. Intuitively, they have the same selfish preferences and possess the same technology for converting policy promises into expected votes.

To characterize the equilibrium policy, we maximize party $A^{\prime}$ 's objective function (3.1) with regard to $q^{A}$, taking $q^{B}$ as given. Exploiting (2.1), (2.2), and (3.5), and evaluating the resulting first-order conditions at the point $q^{A}=q^{B}$, we obtain the conditions which must hold at an equilibrium.

A first result concerns the pattern of redistribution to the voters. The equilibrium involves positive redistribution to group 2 only; that is, $b^{2}>0$, and $b^{1}=b^{3}=0$. This stark result follows as there are more swing voters in group 2 , by our assumption that $s^{2}>s^{1}, s^{3}$, and as the marginal utility of private consumption is constant. Thus both parties target their redistribution programs towards the middle class, because this group contains the most responsive voters. ${ }^{10}$

\footnotetext{
${ }^{10}$ An alternative assumption producing similar results would be to assume that voter turnout differs systematically across groups. In this case, the two parties would unambigously target the group with the highest turnout rate - see Strömberg (1998) for a theoretical treatment of this case (and empirical work suggesting that US groups (regions) with higher voter turnout indeed obtained larger transfers in federal New Deal programs).
} 
The equilibrium supply of public goods then follows from the optimal trade-off between $g$ and $b^{2}$. The corresponding condition is:

$$
s^{2} \cdot 1=\sum_{i} s^{i} \cdot H_{g}(g),
$$

where 1 refers to the marginal utility of private consumption (see 2.1) and superscripts refer to groups. Intuitively, one more unit of redistribution for the middle-class group can be achieved by cutting the supply of the public good by the same amount. This means a gain of votes proportional to $s^{2} \cdot 1$ in group 2 (captured by the LHS), but a loss of votes in every group $i$ proportional to $s^{i} \cdot H_{g}(g)$ (the RHS). It is optimal for the two parties to equate the marginal gain of votes to the marginal loss of votes.

A similar tradeoff, between $t$ and $b^{2}$, pins down the optimal tax rate. An additional unit of redistribution to the middle-class group can also be achieved by raising the tax rate by one third on all voters. This leads to the complementary slackness condition:

$$
s^{2} \cdot 1>\sum_{i} s^{i} \cdot \frac{1}{3}=s \quad[t \leqslant 1] .
$$

Here, the gain of votes in group 2 always exceeds the loss, as $s^{2}=\operatorname{Max}_{i}\left[s^{i}\right]$. Since taxes are not distortionary, the optimum is a corner solution with $t=1$.

Clearly, the more responsive is the middle class group (the higher is $s^{2}$ ), the higher is the opportunity cost of public goods. Thus, the two parties find it optimal to announce a lower supply of public goods and to increase transfers to this powerful group. That is, we have a comparative statics result that will prove useful later, when comparing electoral rules: the larger is the frequency of ideologically neutral middle class voters (the higher is $s^{2}$ ), the smaller is public good provision in equilibrium, and the bigger are the transfers to middle class voters. With distortionary taxes and an interior solution for $t$, as $s^{2}$ increases, the equilibrium tax rate also goes up.

To find the optimal rents implied by the two candidates' platforms, consider finally the tradeoff between $r$ and $b^{2}$. The complementary slackness condition, corresponding to this margin is:

$$
p \gamma \leqslant-[R+\gamma r] \cdot \frac{d p}{d r}=[R+\gamma r] \cdot \frac{s^{2} d}{3 s} \quad[r>0] .
$$

The left-most expression in (3.7) reflects the marginal benefits of extra rents, whereas the remaining expressions reflect the inframarginal rents times the greater 
probability of losing the election. As is evident from the condition, equilibrium rents $r$ can well be positive. As $p$ is equal to $\frac{1}{2}$ in equilibrium, this is more likely when $R$ (the exogenous rents) are low. The reason why electoral competition does not eliminate rent seeking is that the parties are only perfect substitutes for swing voters, but not for any other voters. This implies that $\frac{d p}{d r}$ is negative, but finite. Equilibrium rents are thus larger, the more imperfect substitutes the two parties are; that is, the smaller is the number of swing voters. Hence, we have a second comparative statics result; a larger number of ideologically neutral voters (a higher $s^{2}$ ) reduces equilibrium rents in an interior optimum. Finally, rents are lager, the higher is the variance in electoral outcomes (the lower is $d$ ). Higher variance implies that the expected vote share is not very sensitive to policy anyway; given this, the candidates find it optimal to take a greater risk by insisting on larger rents.

\subsection{Majoritarian elections}

What if elections are instead conducted under plurality rule (first past the post) in single-candidate electoral districts? Specifically, assume that there are three electoral districts and consider the following electoral rule: winning the elections (and setting policy) requires winning at least two districts. One can interpret this setting as a parliamentary election, in which two competing parties have candidates in all three districts. The party who wins in two districts has a majority in the assembly and can thus implement its pre-announced policy. Alternatively, one can interpret it as a Presidential election (as in the US), where a candidate only needs a majority of the votes in a majority of the districts (rather than a majority of the population) to be elected President. We continue to talk of parties (rather than candidates) throughout this section, so implicitly, we adopt the first interpretation which also forms the basis for the empirical work to follow.

We start with a simplifying assumption: the three electoral districts coincide with the three groups in the population. We then show that all comparative politics results easily generalize if groups and districts do not completely overlap. Under majoritarian elections, existence of equilibrium is not guaranteed without further assumptions. Basically, we must assume that the ideological bias towards party $A$ in group 1 and towards party $B$ in group 3 are large enough; that is, the group-specific means $\bar{\sigma}^{1}$ and $\bar{\sigma}^{3}$ are sufficiently distant from zero. If this is the case, an equilibrium exists where $A$ and $B$ announce equal policies and where the entire competition takes place in the "marginal district" made up of the middle 
class (group 2) voters. Party $A$ wins district 1 with large enough a probability and loses district 3 with large enough a probability, so that neither candidate finds it optimal to seek voters outside the marginal district; recall that only two districts are required for winning the election. ${ }^{11}$

Under these assumptions, the relevant expression for party $A^{\prime}$ s probability of winning can be written as:

$$
p^{A}=\operatorname{Prob}\left[\pi^{A, 2} \geq \frac{1}{2}\right]=d \cdot\left[W^{2}\left(q^{A}\right)-W^{2}\left(q^{B}\right)\right]+\frac{1}{2} .
$$

Compared to (3.5), the expression in (3.8) depends only on what happens in

\footnotetext{
${ }^{11}$ We want to show that $A$ does not want to seek victory in district 3 (party $A$ is already winning district 1 with higher probability than district 2, which party $A$ wins with $50 \%$ probability in the proposed equilibrium).
}

Let a $\sim$ denote a deviation to district 3 . A deviation does not pay for party $A$ if:

$$
\tilde{p}^{A, 3}\left[R+\gamma \tilde{r}^{A, 3}\right] \leq \frac{1}{2}\left[R+\gamma r^{A, 3}\right] .
$$

Taking into account the first-order conditions for $\tilde{r}^{A, 3}$, (F1) can be rewritten as:

$$
\left[2 \tilde{p}^{A, 3}\right]^{2} \leq \frac{s^{3}}{s^{2}}
$$

Moreover, by the definition of $p^{A, i}$ and noting that if groups coincide with districts a deviation to district 3 does not alter the supply of public goods $g$ offered by the deviating party, we have

$$
\tilde{p}^{A, 3}=\frac{1}{2}-d \bar{\sigma}^{3} .
$$

Hence, by (F3) and (F2):

$$
\frac{1-\sqrt{\frac{s^{3}}{s^{2}}}}{2 d} \leq \bar{\sigma}^{3} .
$$

Clearly, for $\bar{\sigma}^{3}$ high enough, this necessary and sufficient condition is satisfied.

Note, however, that we also want the three groups to overlap (cf. Figure 1). Hence, we also want:

$$
\bar{\sigma}^{3} \leq \frac{1}{2} s^{3} .
$$

Are (F4) and (F5) compatible with each other? They are, if:

$$
1 \leq d s^{3}+\sqrt{\frac{s^{3}}{s^{2}}} .
$$

Similar conditions on $\bar{\sigma}^{1}$ insure that party $B$ does not want to deviate from the proposed equilibrium, either. 
the marginal district, district 2. The other districts are neglected, because there party $A$ is either very likely to win or very likely to lose. We may then follow the same steps as in the previous subsection to characterize the policies in a convergent electoral equilibrium. Obviously, only the middle class - the sole group in the marginal district - gets all the redistribution. Furthermore, it is optimal for both candidates to propose more redistribution than under proportional elections. Intuitively, the benefit to the parties of such redistribution is the same as under proportional elections, namely the marginal votes gained from the middle class voters. But the costs are smaller, as the parties now do not internalize the votes lost in the non-marginal districts.

As a result, it is still optimal to set the tax rate at its maximum: $t=1$. With distortionary taxes, however, the lower costs of taxation would have led to a higher tax rate. The sharper incentives to redistribute also show up in the optimal supply of public goods, as the optimal tradeoff between $b^{2}$ and $g$ now fulfills:

$$
s^{2}=s^{2} \cdot H_{g}(g)
$$

By $(3.9), H_{g}(g)=1$, whereas by $(3.6) H_{g}(g)<1$ under proportional elections. Thus the supply of public goods is smaller under majoritarian elections.

Finally, equilibrium rents are also smaller. To see this, note that the condition for $b^{2}$ vs. $r$ now becomes:

$$
p \gamma \leqslant-[R+\gamma r] \cdot \frac{d p}{d r}=[R+\gamma r] \cdot d \quad[r>0] .
$$

The condition is identical to (3.7), except that $d$ replaces $\frac{s^{2} d}{3 s}$ in the expression for $-\frac{d p}{d r}$. Since $s^{2}<3 s=\sum s^{i}$, higher rents make the candidates lose votes at a higher rate in majoritarian elections. Intuitively, the electoral competition is stiffer, as it is now focused on the district with the most responsive voters. Because the election outcome is more sensitive to policy, the two parties become more disciplined and forego some prospective (endogenous) rents.

What happens to these comparative politics results, if we relax the extreme assumption about perfect overlap between groups and districts? Qualitatively, the answer is "nothing", provided that the middle-class group 2 is a "dominant group" in one of the districts. ${ }^{12}$ Let the population share of group $i$ in district $k$ be denoted by $n^{i, k}$. Then, group 2 is a dominant group in one of the districts if

\footnotetext{
${ }^{12}$ The conditions for existence of equilibrium become stricter as we relax the assumption of perfect overlap.
} 
$n^{2, k}>\frac{1}{3}$ and $n^{1, k}, n^{3, k}<\frac{1}{3}$ in some $k$. If the middle class dominates district 2 , in this sense, electoral competition will take place only in district 2. Furthermore, district 2 is an asymmetric replica of the whole population, where group 2 receives more weight. As illustrated in Figure 2, this asymmetry has the same effect as a higher relative density $\frac{s^{2}}{3 s}$ of group 2 under proportional elections, the result of which was discussed in subsection 3.2; more redistribution towards group 2, less public goods, and less rents. ${ }^{13}$

\section{Insert Figure 2 about here}

The central comparative politics results of this section can be succinctly summarized. Majoritarian elections make electoral competition stiffer, by concentrating it in some key marginal districts. The result is more targeted redistribution in a more narrow constituency. With majoritarian elections, we should therefore not only observe more targeted redistribution towards the politically influential middle class, but also a lower supply of public goods and smaller rents, ceteris paribus. Extending the model with distortionary taxes, we also get the prediction that majoritarian elections should be associated with larger governments.

Before turning to the evidence, however, we discuss a different model of political behavior, which focuses on institutions governing policy formation.

\section{Post-election politics}

We now drop the unrealistic assumption that binding commitments to policy platforms can be made ahead of elections. In the real world, there is no outside authority that can enforce campaign promises. And even if there was (or if reputational incentives were strong enough), many policy-relevant states of the world are non-describable or non-verifiable. Precise state-contingent policy promises can thus not be formulated or would not be believed by the voters. This suggests that political constitutions are analogous to incomplete contracts; they allocate decision rights to different actors. Policy choices are made by incumbent politicians, once in office, so the elections select a decision maker, not a state contingent policy. In particular, voters hold politicians accountable for their performance through retrospective voting.

\footnotetext{
${ }^{13}$ Formal results are available from the authors upon request.
} 
In this setting, it is natural to redirect the focus onto the institutions governing policy formation. Such institutions determine which control rights are associated with which political office, and hence lay out the rules for legislative bargaining among politicians. We ask how these rules - the political regime - resolve the conflicts between voters and politicians, contrasting presidential and parliamentary regimes, drawing on results by Persson, Roland and Tabellini (1998a and b). That analysis, in turn, builds on several strands of earlier work. As in Barro (1973) and Ferejohn (1986), voters limit the agency problems associated with rentseeking politicians by holding them accountable through retrospective voting. As in Persson, Roland and Tabellini (1997), the rules for separation of proposal (and veto) powers shape the conflicts between different politicians. And as in Diermeier and Feddersen (1998), the rules for executive formation and dissolution shape the coalition formation within the political system.

\subsection{General features}

We consider a majoritarian electoral system throughout. As in Section 3.3, there are three equally-sized districts. Each of them elects a single politician. We now assume a more strongly dominant group of voters in each district: in our earlier notation $n^{i, k}>\frac{1}{2}$ for each group $i$ in one of the districts $k$. The preferences of this dominant group determine the election result and we need not distinguish between districts and groups.

Policy choices are made by the three incumbent legislators in legislative bargaining, before elections take place. These politicians aim at maximizing the sum of current endogenous rents and expected future exogenous rents of office:

$$
E\left(u^{i}\right)=\gamma r^{i}+p^{i} \cdot R
$$

As previously, $p^{i}$ is the probability that politician $i$ is re-elected, while $R$ denotes the exogenous "ego-rents" associated with winning the election. Moreover, $r^{i}$ denotes the current endogenous rents of politician $i$. This adds an additional policy dimension, namely the allocation of total rents $r$ among incumbent politicians and, accordingly, a conflict of interest among incumbent politicians. Note that $r^{i}$ is enjoyed irrespective of the election result, while $R$ is conditional on winning the elections. Hence, there is an implicit intertemporal dimension: $R$ refers to the future, while $r^{i}$ refers to the current period. ${ }^{14}$

\footnotetext{
${ }^{14}$ Persson, Roland and Tabellini (1998a) demonstrate how the value of re-election $R$ can be endogenized in an infinite-horzion model, as the present discounted value of expected future endogenous rents.
} 
We now abstract from ideological or personal attributes of different politicians. In each district, the incumbent legislator thus faces an opponent, who is identical in the eyes of the voters (the terms $\delta+\sigma^{j}$ appearing in (3.2) are dropped). Voters in each group coordinate on optimal retrospective voting strategies. Specifically, voters in district $i$ choose optimally a reservation utility $\varpi^{i}$ for re-electing the incumbent legislator. That is, they vote according to:

$$
p^{i}=\begin{array}{ll}
1 & \text { if } \quad w^{i} \geq \varpi^{i} \\
0 & \text { otherwise. }
\end{array}
$$

While coordinating within the group, the voters do not cooperate across groups. Thus, the reservation utility $\varpi^{i}$ chosen by group $i$ is a best response to the reservation utility $\varpi^{j}$ simultaneously chosen by group $j \neq i$. Moreover, we assume throughout that voters have full information and that they take the political power of their legislator into account when formulating their voting rule.

In this setting, the incumbent politicians have significant discretionary powers to claim rents for themselves. But given their objectives in (4.1), the voting rule (4.2) presents them with an intertemporal tradeoff; if the politicians extract too high rents today, they cannot satisfy the voters' demands and must forego reelection and rents tomorrow. The incentive scheme inherent in this accountability mechanism is less effective, however, if the decisive politician has access to more revenue, as this increases the temptation to appropriate the revenue for his private agenda.

\subsection{Presidential regimes}

We start by analyzing "presidential" regimes. Such regimes have two important institutional features. First, effective decision making power is split among different politicians, who are separately and directly accountable to the voters. This strengthen the "checks and balances" against political abuse and collusion among politicians. Second, the maintenance of such powers does not depend on a confidence vote, or more generally on majority support in the assembly. This, in turn, weakens the incentives to maintain stable coalitions in the assembly. Specifically, valuable proposal powers are not - like in the parliamentary regimes below - concentrated in a cabinet-style executive, which must rely on continued confidence of a majority in the legislature. Instead, the executive typically derives its mandate directly from the voters. The separation of powers may be between the president and Congress, or between different politicians in Congress. 
For example, the US fits both the aforementioned features; it has a directly elected president, and proposal powers over (economic) legislation are dispersed across powerful Congressional committees. As a result, legislative coalitions are rather unstable; we often observe different Congressional majorities forming over different policy issues, and relatively little party discipline. France, on the other hand, has neither of these features. Despite its popularly elected president, the proposal powers over (economic) legislation are concentrated in the cabinet, the survival of which depends on continued support from a majority in the National Assembly. For this reason, France is not classified as a Presidential, but a Parliamentary, democracy in the empirical analysis below.

We formulate a simple legislative bargaining game that seeks to capture these features. Different politicians, directly accountable to the voters, are assigned very sharp proposal powers over different policy dimensions. One of these, $a_{t}$, proposes the budget size. The other, $a_{e}$, proposes the budget allocation among alternative uses. One may think of these two politicians as the "tax committee" and the "expenditure committee". ${ }^{15}$ A sequential "budget procedure" provides checks and balances and ensures effective separation of powers. Any majority can be formed to approve these proposals, and different majorities can be formed on each of the separate proposals. The specific timing is illustrated in Figure 3.

Three politicians, $i=1,2,3$ share office at the start of the period. Two of them are exogenously chosen to act as $a_{t}$ and $a_{e}$. Having observed the role of their legislator, voters in all districts simultaneously formulate their reservation utilities, $\varpi^{i}$. Then $a_{t}$ makes a "take it or leave it" proposal on the budget size, $3 t$. This proposal is voted upon by congress, namely by $a_{t}, a_{e}$ and the third politician. Any majority is free to form. If the proposal is approved by at least two politicians, it is implemented. Otherwise an exogenous status quo tax rate, $t^{s}$, in enacted. Next, $a_{e}$ proposes an allocation of expenditure, subject to the budget determined in the previous node of the game. Again, a vote is taken, and any majority can form. An exogenous default allocation (unattractive for the voters) is implemented if the proposal is rejected. Finally, having observed everything that has taken place before, voters decide whether or not to reappoint the incumbent politician in their district.

\footnotetext{
${ }^{15}$ We thus abstract from the existence of a president with veto or proposal powers, but these could be introduced without changing the thrust of the main results. We could also further split the proposal power over spending, giving some agenda-setting privileges to each of the three legislators, without changing the main results.
} 


\section{Insert Figure 3 about here}

This game has a unique subgame-perfect equilibrium. We now discuss its properties, without formally deriving any of the results. In doing so, we focus on the central trade-offs that must be resolved by the optimal choices of incumbent legislators and voters. A formal derivation is provided in Persson and Tabellini (1998) and, for a more general infinite horizon model, in Persson, Roland and Tabellini (1998a).

Consider the allocation of spending proposed by $a_{e}$, for a given budget size. Getting the support from a legislator typically requires spending additional resources, either on rents for him, or on transfers for his district (so that he can satisfy his re-election constraint), or both. Hence, $a_{e}$ seeks a minimal winning majority, namely the support of only one legislator for his spending proposal. Moreover, he seeks the support of the legislator who is "cheapest to buy", namely whoever demands the least either for himself or for his voters. This pits the other two voting districts against each other: the voters in the districts $i \neq a_{e}$ pay taxes anyway, but receive zero transfers if they are left out of the winning coalition. Hence, they become engaged in a "Bertrand competition" for the spoils allocated by $a_{e}$. To increase the chance of their representative being included in the winning coalition, they reduce their reservation utilities $\varpi^{i}$ down to the point where they drive the demand for redistribution down to zero. Any equilibrium thus has:

$$
b^{i}=0, \quad i \neq a_{e} .
$$

This property leaves $a_{e}$ free to please his voters. Namely, all redistributive transfers go to his district $\left(b^{i}=b\right.$ if $\left.i=a_{e}\right)$. And the public good is traded off against redistribution, one for one. This leads to severe under-provision of the public good, since only one third of the social benefits are internalized. Specifically, in equilibrium: ${ }^{16}$

$$
H_{g}(g)=1 \text {. }
$$

What about equilibrium rents? The voters would like to keep them down to a minimum. The best they can do is to set their reservation utility, so that:

$$
\gamma r+2 R=\gamma 3 t
$$

\footnotetext{
${ }^{16}$ A social optimum, fulfilling the Samuelson criterion would have $H_{g}(g)=\frac{1}{3}$. Note that the equilibrium coincides exactly with the equlibrium public goods provision in the majoritarian electoral system studied in Section 3.3.
} 
The right-hand side of (4.3) is the maximum joint payoff to $a_{e}$ and his coalition partner if they go for the short-run option of allocating the entire budget to rents for themselves, only to be kicked out of office. The left-hand side of (4.3) is the joint payoff to $a_{e}$ and his coalition partner if they decide to seek reappointment and please their voters. In this case, they get current rents $\gamma r$ plus future exogenous rents $2 R$ (as both politicians are re-elected). Thus, voters cannot push the endogenous rents $r$ below the value implied by (4.3). If the value of reappointment $R$ is not very high, then by (4.3) equilibrium rents can be positive. Intuitively, such positive equilibrium rents reflect the contract incompleteness and the resulting discretion enjoyed by politicians, once they are in office. Concerning the allocation of rents among politicians, it is optimal for $a_{e}$ to exploit his agenda-setting power, nailing the junior coalition partner to his status-quo payoff.

Last, what about equilibrium taxes? Recall that taxes are proposed by the taxation committee, $a_{t} \neq a_{e}$. The voters of this legislator do not benefit from additional tax revenue beyond what is necessary for financing the equilibrium supply of the public good and minimum rents. Additional taxes go either to redistribution for district $i=a_{e}$, or to rents for the politicians. These voters thus want to keep taxes at a minimum. Likewise, legislator $a_{t}$ has only limited claims on tax revenue. He is therefore pleased to satisfy his voters and go along with low taxes, so as to earn re-election. In other words, neither $a_{t}$, nor the voters re-electing him, are residual claimants of a larger budget. As a result, equilibrium taxes are relatively low and unambiguously:

$$
t<1 \text {. }
$$

That is, voters exploit the separation of powers to discipline politicians and enforce a small size of government.

We can summarize these results as follows. Presidential regimes induce strong competition among the voters, implying redistribution towards a minority. This, in turn, raises the opportunity cost for public goods which are severely underprovided.. Voters not benefiting from the minoritarian redistribution demand low taxes. Presidential regimes, with their separation of powers, also entail strong competition between incumbent politicians. This conflict can be exploited by the voters to limit the agency problem. Together, these features imply relatively low taxes and a small size of government. 


\subsection{Parliamentary regimes}

We now turn to "parliamentary" regimes. There are two central features of such regimes: proposal powers over legislation rest mainly with the government, and, government survival depends on the support of a majority in the assembly. These two features give the majority coalition strong incentives to stick together; a break up could lead to a government crisis and result in the loss of valuable proposal powers. In the language of Diermeier and Feddersen (1998), parliamentary systems exhibit legislative cohesion, a tendency towards stable coalitions in the assembly. This could be reflected either in party discipline - that is, cohesion between different factions within a party - or in the stability of coalitions made up of different parties.

To capture these features, we modify the previous game in two important respects. First, we assign veto rights to the two members of the majority coalition over the final policy package. Second, a costly outcome (i.e. a government crisis) is triggered for the majority coalition if the veto is exercised. As a result, the agenda setter is not free to seek support from the legislator who is "cheapest to buy", but needs to please his coalition partner. The timing is illustrated in Figure 4. Two different (exogenously appointed) legislators, labeled $a_{t}$ and $a_{e}$, control the proposals on taxes and expenditures. One may think of these as cabinet ministers. No vote is taken, however, until both proposals have been made. A veto by any of the coalition partners triggers a government crisis, which leads to a low expected utility both for the politicians and the voters. ${ }^{17}$ These assumptions approximate the proposals being made by cabinet ministers in a budget preparation phase inside the government, with a vote of confidence being attached to the final budget proposal.

\section{Insert Figure 4 about here}

What does the equilibrium look like? As bargaining power here is more equally shared among the coalition partners, the final allocation splits welfare

\footnotetext{
${ }^{17}$ The given expected utilities following a government crises can be generated as continuation values in a subgame, with either a caretaker government or with a new government formation phase, as in Diermeier and Feddersen (1998) and in Persson, Roland and Tabellini (1998a). Obviuosly, the precise rules for government break-up and the procedure after a government crisis affects the bargaining power of the coalition partners and therefore the legislative outcome; Baron (1998) formally models some of the alternatives and their consequences.
} 
more equally among voters in the majority coalition, as well as among their politicians. In particular, the equilibrium allocation of redistributive transfers and public goods must be jointly optimal for voters in the majority coalition. This generally leads to redistribution in favor of a majority, and the benefits of the public goods for the majority are internalized. That is, we have:

$$
\begin{aligned}
b^{i} & \geq 0, \quad i=a_{t}, a_{e} . \\
\frac{1}{2} & \leq H_{g}(g) \leq 1
\end{aligned}
$$

with $H_{g}(g)=\frac{1}{2}$ if $b^{i}>0$ for both $i=a_{t}, a_{e}$.

The equilibrium is not unique, however. Since voters set their reservation utilities simultaneously, welfare can be split among these in many different ways. That is, bilateral monopoly now replaces Bertrand competition in the redistribution game between voters. All the equilibria satisfy (4.4). Hence, in all of these (except one at most) public-good provision is higher than in the Presidential system, and in most of these redistributive transfers benefit a majority of voters.

Voters in the majority now benefit from higher taxes, at the expense of the minority. Both legislators in the coalition are pleased to go along with high taxes. As a matter of fact, even if the voters wanted lower taxes, the legislators would not deliver them. The lack of effective separation of powers in the Parliamentary regime implies that politicians in the coalition compete less fiercely over rents. Unlike in the Presidential regime, higher tax revenue brings about larger equilibrium rents for both politicians, not just for $a_{e}$. Thus, in equilibrium, $a_{t}$ proposes

$$
t=1
$$

$a_{e}$ is pleased to accept the proposal, and voters in their districts are pleased as well.

Higher tax revenue brings about larger endogenous rents. By analogy with (4.3), total rents now satisfy:

$$
\gamma r+2 R=\gamma 3
$$

which implies a higher $r$ than in the Presidential system, since the right-hand side of (4.5) is larger than that of (4.3), while $R$ and $\gamma$ are the same.

We can summarize the central comparative politics results from our analysis of post-election politics. Compared to presidential regimes, parliamentary regimes have less competition among the voters. Redistributive transfers benefit a majority, rather than a minority. The supply of public goods is higher, as the politicians 
are induced to internalize the benefits for a larger coalition of voters. Parliamentary regimes also have less competition between the politicians who make policy proposals. The agency problem between voters and their representatives thus becomes more pronounced, as manifested in larger equilibrium rents. Altogether, a majority of voters and politicians benefit from higher taxes, so parliamentary regimes are associated with larger governments.

We close our theoretical analysis with a final remark. Despite the different assumptions, there is an important analogy between this comparative politics result and that obtained in the model of pre-election politics. Both in the pre-election politics and in the post-election model, political institutions determine the extent of competition among voters or politicians. More competition always brings about a lower supply of public goods as the benefits of fewer voters are internalized. In fact, the more competitive systems, namely the majoritarian electoral rule and the presidential regime, both imply that only a third of the voters' preferences get internalized in the policy decisions. They therefore bring about exactly the same supply of public goods (satisfying $H_{g}(g)=1$ ), even though the mechanisms leading to this outcome are different. In both cases, more competition also brings about smaller rents (as the agency problem is less harmful to the voters). This analogy suggests that from a normative point of view, political competition can be good or bad: it may be good for public good provision, but bad for the agency problem. Hence, a universally optimal constitutional form may not exist. Designers of constitutional reforms may face a tradeoff, and different societies may be better off with one or another institutional feature. This conclusion is consistent with the large varieties of political constitutions that we observe in the real world.

We exploit such observed variety in the next, empirical, section.

\section{Evidence}

In this section, we present some empirical evidence on the size and scope of government. In particular, we confront some of the predictions from our two models with cross-country data. We start by briefly describing our sample and our classification of political systems. Next, we turn to residuals from cross-country regressions of the size of government and public goods provision onto socio-economic control variables, asking whether these residuals differ systematically across regime types and electoral rules. Finally, we present results from regression analyses, where characteristics of the political system enter among the independent variables explaining government expenditure. 


\subsection{The sample}

The previous models predict how the electoral rule and regime type influence the size and scope of government in democratic countries. As we want to exploit variation with regard to the political system, and at the same time hold various socio-economic variables constant, we deliberately choose a generous definition of democracy so as to increase the sample size. Specifically, we only include countries scoring between 1 and 5, on average, over 1985-90, according to Gastil's well-known index of political rights. This selection rule produces a sample of 64 countries, depicted by non-white entries on the world map in Figure $5 .{ }^{18}$ Note that the dating of the democracy information, which is dictated by the availability of government expenditure data, excludes the new democracies in Eastern Europe.

\section{Insert Figure 5 about here}

The theoretical model of majoritarian elections assumes plurality rule in singlecandidate districts. We therefore classify all countries electing their legislatures according to those rules as majoritarian. This amounts to a total of 29 countries, indicated by dark shade on the map. The other 35 countries in the sample are classified as proportional, indicated by light shade. We have also devised a more continuous measure, attempting to capture the degree of proportionality (see below). Our primary source for data on the number of candidates per district is Cox (1997).

According to the theory, presidential regimes have two important features. First, there is effective separation of powers between the executive and legislative branches of government. Second, maintenance of proposal powers by specific decision makers does not depend on the support of a majority in the assembly. To discriminate between parliamentary and presidential democracies in our sample, we consider: (i) the degree of authority of a popularly elected president over the cabinet; (ii) the extent to which the survival of the executive and assembly powers are separate. Despite a popularly elected president, a country is classified as parliamentary, if the president has little authority over the cabinet, or if executive survival depends on maintained support from a majority in the legislature

\footnotetext{
${ }^{18}$ On a scale from 1 to 7, Gastil (1987) classifies countries scoring 1-2 as "free", and those scoring 3-5 as "semi-free". Borderline cases in our sample include countries such as Chile, Paraguay, Egypt, and Malaysia.
} 
throughout the election period. Also, presidential powers to dissolve the legislature weaken separation of powers between the two bodies, and thus contribute to classifying a country as parliamentary. ${ }^{19}$ The primary source for this information is Shugart and Carey (1992, ch. 8). Altogether, we end up with 39 parliamentary democracies, indicated by solid on the map, and 25 presidential democracies, indicated by striped on the map. Many, but not all, presidential democracies are found in Latin America. A complete and detailed data set of our regime types, electoral rules and other data is under preparation and will be made available soon.

As noted in the Introduction, government size is measured as total expenditures of central government in percent of GDP, averaged over the period 1988-92. The primary data source is IMF's Government Financial Statistics, but we have also collected data from other sources. We rely on data for central government, rather than general government, since they are available for a larger number of countries. Such data admittedly do not take variation in decentralization to local governments into account, a problem we try to remedy by including measures of centralization among our control variables. Anyway, the theory assumes decisions to be under centralized political control, which better fits central (rather than general) government expenditures. Data on public goods expenditure are not directly available. We create such measures by aggregating data on expenditure categories which, a priori, should have a high public-good content. Thus, our measure of public goods is the sum of expenditures on transportation, education and order and safety, also in percent of GDP. We also experiment with broader measures of spending on public goods. ${ }^{20}$

Finally, we use a number of socio-economic control variables, found in previous empirical studies to be correlated with the size of government. When explaining the size of government, our most parsimonious list of controls, denoted $X^{B}$ in the Tables below, includes the following variables: (i) the log of per capita income, as the level of development could influence the voters preferences for private versus public consumption, as well as the availability of tax bases, as conjectured by the so called "Wagner's law" (cf. Mueller (1989)); (ii) the log of openness, measured

\footnotetext{
${ }^{19}$ Following the theory in this way, means that France - where the government, holding proposal powers over economic policy, is dependent on the legislature - is classified as parliamentary, whereas Switzerland - where the coalition government is not dependent on the legislature - is classified as presidential.

${ }^{20} \mathrm{We}$ also tried to include defense spending in our public goods measure. Military spending varies greatly over countries, however, and we did not succeed in finding good control variables to pick up the underlying geopolitical and historical factors explaining this variation.
} 
as the log of the sum of exports plus imports in \% of GDP, as suggested by the earlier empirical work by Cameron (1978) and Rodrik (1998) and also to capture the greater availability of tax bases in less developed open economies (cf. Goode (1984)); (iii) the share of the population above 65, which determines spending on pensions and health (see, e.g., the empirical findings in Lindert (1996); (iv) a measure of ethno-linguistic fractionalization, to capture the idea that political interaction is more difficult in more fractionalized countries which could affect public policy decisions (see, in particular, the empirical work by Alesina, Easterly and Baqir (1997) and by Easterly and Levine (1997)).

When explaining public good provision, the list of parsimonious controls, now denoted $Z^{B}$, is defined as $X^{B}$ above, except that the index of fractionalization is replaced by: (iv) centralization of government spending (measured as expenditures of central government divided by expenditures of general government), as the assignment of tasks to various levels of governments could differ across countries (Panizza (1997) also used this variable). Below, we comment on what happens when these sets of regressors are expanded to include other variables.

\subsection{Analysis of residuals}

Graphs 1 and 2 in the Introduction display the residuals generated by regressions of the size of government and public good provision against the parsimonious controls $X^{B}$ and $Z^{B}$ defined above. ${ }^{21}$ What is the pattern of these residuals across different political systems?

${ }^{21}$ Specifically, the residuals for government size have been generated by the regression

$$
\begin{aligned}
S I Z E= & -14.08(-0.73)+0.02(0.01) \cdot I N C O M E+ \\
& 8.01(4.23) \cdot O P E N+152.9(3.51) \cdot O L D \\
& -0.06(-1,24) \cdot E T H N O
\end{aligned}
$$

where the regression coefficients ( $t$-statistics in brackets) refer to the variables in $X^{B}$ (which appear in the same order as they are described in the text above); this regression is based on 54 observations and has an adjusted $R^{2}$ of 0.57 .

Similarly, the residuals for public goods have been generated by the regression:

$$
\begin{aligned}
P U B= & -4.20(-0.60)-0.64(-0.86) \cdot I N C O M E+ \\
& 3.27(3.81) \cdot O P E N+7.22(0.44) \cdot O L D \\
& +0.04(1.23) \cdot C E N T R
\end{aligned}
$$

where the coefficients refer to the variables in $Z^{B}$; this regression is based on 40 observations and has an adjusted $R^{2}$ of 0.46 . 
Before answering this question, it is useful to recall the hypotheses suggested by the theory. Consider first the size of government. The post-election politics model of Section 4 suggested that presidential regimes should be associated with smaller governments, ceteris paribus. We should thus observe predominantly negative residuals for presidential regimes and predominantly positive residuals for parliamentary regimes. The pre-election politics model of Section 3 had no immediate prediction, but an extension with distortionary taxes suggested that majoritarian elections should be associated with larger governments, ceteris paribus. If this is correct, we should expect negative residuals for countries with proportional elections and positive residuals for those with majoritarian elections. ${ }^{22}$

We summarize these predictions at the top of Graph 3. At the bottom, we display the residuals in each of the four political systems implied by our two-way empirical classification (observations are colored in the same way as in the map of Figure 5). The graph indeed indicates clear support for the post-election politics prediction: negative residuals dominate for the countries with presidential regimes (the striped observations to the right), whereas positive residuals dominate for the countries with parliamentary regimes (the solid observations to the left). It also indicates some, but weaker, support for the pre-electoral politics prediction; majority elections (darker observations) are associated with positive residuals, particularly in parliamentary regimes, whereas proportional elections (lighter observations) are associated with negative residuals, particularly in presidential regimes.

\section{Insert Graph 3 about here}

Next, consider the predictions for public good provision. Recall that our postelection politics model suggested that presidential regimes should be associated with a smaller supply of public goods than parliamentary regimes. Our preelection politics model suggested that majoritarian elections should be associated with a smaller supply of public goods than proportional elections. We summarize these predictions at the top of Graph 4. The residuals at the bottom indicate some support for the latter hypothesis; countries with majoritarian (proportional)

\footnotetext{
${ }^{22}$ We are thus implicitly treating our predictions from the two theoretical models as additive, which is not necessarily appropriate. For instance, our post-election model in Section 4 assumes majoritarian elections and we do not - strictly speaking - know whether its predictions are valid under proportional elections.
} 
elections indeed seem associated with negative (positive) residuals. But it is harder to discern systematic differences in the regime dimension.

\section{Insert Graph 4 about here}

Overall, these graphs support some of the theoretical predictions, though not all of them. In particular, the residuals suggest that presidential regimes have smaller governments, and perhaps that majoritarian electoral systems tend to have less public good provision. But while these graphs are suggestive, they still leave several questions open. Are the differences across political regimes statistically significant? If so, are the results robust to different specifications of the control variables, and to different measures of the dependent variables? If the political systems are correlated with the controls, how should the covariance with government spending be attributed? To address these questions, we now turn to some regression analysis.

\subsection{Regression analysis}

Table 1 gives a selected set of results from cross-country regressions on government size. All equations are estimated with OLS. The dependent variable is total expenditures, either by central government (columns 1-5), or by general government (columns 6 and 7). All regressions include the parsimonious set of control variables described in the previous subsection, called $X^{B}$. We also exploit a set of extended controls $X^{E}$, that also adds the $(\log )$ of population size and our measure of centralization to $X^{B}$ (column 4). Finally (in column 5), we include a set of dummy variables $C$ for the OECD, Latin America, Asia and Africa. ${ }^{23}$ The table displays the regression coefficients for dummy variables reflecting the political system; PRES is set to 1 for presidential and 0 for parliamentary regimes, MAJ is set to 1 for majoritarian and 0 for proportional elections, MAJPRES is set to 1 for presidential regime cum majoritarian elections and 0 otherwise, and so on. Numbers within brackets are $t$-ratios for a test of the null hypothesis that the corresponding regression coefficient is equal to zero. These are estimated using

\footnotetext{
${ }^{23}$ We also experimented with other variables, such as a measure of income inequality and the share of young people in the population, but they were generally statistically insiginficant and did not change any of the results.
} 
White's (1980) consistent estimator. ${ }^{24}$ Finally, we list the number of observations and the adjusted $R^{2}$ for each regression.

\section{Insert Table 1 about here}

Our results confirm the visual impression from Graph 3. The presidential dummy is significant in all specifications. Furthermore, the implied differences are substantial; the size of government is about 10 percentage points smaller in presidential regimes, a large number given that the average size in the sample is just below 29 per cent. The majoritarian dummy, on the other hand, is smaller in absolute value and less significant, though of the expected sign. The specifications, including a finer classification of the political system, confirm these results.

Table 2 illustrates the results of regressions on public goods. Once more, all equations are estimated with OLS. The dependent variable is the sum of central government expenditures on order and safety, transport and education (columns 1-6), or a wider aggregate also incorporating expenditure on health (column 7). All regressions include the parsimonious set of control variables described in the previous subsection, $Z^{B}$. We also use an extended set of controls $Z^{E}$ that adds to $Z^{B}$ the $(\log )$ of population, and the index of ethno-linguistic fractionalization (columns 5-6), or the set of dummies $C$ for OECD, Latin America, Africa and Asia (column 6). As in Table 1, we display the regression coefficients for dummy variables indicating the type of political system and the corresponding (Whiteadjusted) $t$-ratios. We also include (column 4) MAJORIT, a continuous measure of (inverse) proportionality of the electoral system, taking a minimum of 0 and a maximum of $1 .^{25}$ The expected sign of the coefficient on this variable is therefore negative.

\section{Insert Table 2 about here}

\footnotetext{
${ }^{24}$ Standard errors estimated with OLS are not very different. The regression results are also very similar, if observations are weighted by GDP per capita.

${ }^{25}$ The measure is 1 (Average district magnitude), where Average district magnitude is obtained from the information about the electoral system in Cox (1997). The value of this measure in our sample ranges from $\frac{1}{150}$ in the Netherlands (where all 150 legislators are elected in one nation-wide district) to 1 in the majoritarian countries (where each legislator is elected in a single-candidate district).
} 
Here, the results are more fragile, and do not always confirm the visual impression from Graph 4. The majority dummy, as well as MAJORIT, has a negative estimated coefficient in all specifications but one. The estimate is generally around -1.5, suggesting that majoritarian elections are associated with a supply of public goods which is about 1.5 percentage points lower. This, again, is not a negligible difference, considering that the average in the sample is just above 8 per cent. But the estimated coefficient is statistically significant only when the majoritarian dummy is interacted with the presidential dummy, or when the continental dummies are included. Inspection of the residuals reveals the existence of a large outlier country, Botswana, a majoritarian parliamentary system with large spending on public goods. When this country is excluded from the sample (or when the dummy for Africa is included), the estimated coefficients and the $t$-ratios on the MAJ dummy and on MAJORIT become more negative, as predicted by the theory, and are statistically significant at the $5 \%$ level. The results are also sensitive to the specification, however. As illustrated in column 5, when the set of controls is expanded to $Z^{E}$, the political dummy changes signs and does not significantly differ from zero. This feature of the evidence does not depend on outlier countries, and the results do not improve significantly when Botswana is excluded. Similar results hold for the broader measure of public goods, as illustrated in the last column. Finally, the estimated coefficients for the presidential dummies generally have the sign predicted by the theory. But these are only statistically significant when interacted with the electoral system. Overall, the evidence from the regressions on public good provision is not inconsistent with the theory but seems too fragile to draw any reliable inference. The predictions from our models regarding public goods should thus be investigated further, perhaps with better measures of public good provision.

\section{Closing remarks}

Our analysis raises many questions. The empirical results are still preliminary. Their robustness should be checked more carefully with regard to sample selection, omitted variables, measurement error, and other statistical problems. Moreover, additional implications could also be tested, for instance exploiting available data on government corruption (see in particular the recent work by Mauro (1998)). We believe, however, that some of the empirical results of this paper are likely to hold up. In particular, we have confidence in the finding that presidential regimes are associated with smaller governments. 
The two simple models we have studied may reflect the current state of the art, but they fail to capture important aspects of political interactions. For example, we treated the pre-election policy announcements and the post-election policy choices as entirely separate phenomena. It is not obvious how they should be linked. Under the plausible assumption that binding policy commitments cannot be made, pre-electoral announcements influence post-election choices only if they are self-enforcing, due to reputational concerns of some form. But whose reputation is more important? Generally speaking, we believe that the collective reputation of political parties is more important than the individual reputation of single politicians. But this raises another difficult question: how should the collective choices of political parties be modeled? In our analysis, as in virtually all of the literature, there is no meaningful distinction between a party and a politician. On a final point, our models were designed to shed light on the stark cross-section variation in the data on government spending. Would similar models be useful in shedding light also on the stark time-series variation we observe in the same data, particularly the well-documented growth of government and the expansion of transfer payments in the last 30 years? This is far from obvious.

We intended this lecture to illustrate how we - as economists - might embark upon new research on comparative politics. We believe such research should rely on solid theoretical foundations and aim at strong empirical content. In our view, the theory is challenging, but doable. Indeed, researchers have recently made progress in understanding the consequences of different rules for allocating decision-making authority over legislation and government formation. Empirical content is essential, in more than one way. Constitutions across the world provide a great deal of observable variation that can provide precise empirical guidance when formulating extensive-form game theoretic models. This may help avoid the "with-the-right-assumptions-you-can-prove-anything-critique", sometimes launched against game-theoretic research in Industrial Organization. Moreover, the theory can, and should, be formulated to yield predictions over observable policy variables. New or better data on political institutions or measures of government performance may be necessary; but a strong theoretical backing would greatly facilitate primary data collection. Collaboration between economists and political scientists on the boundary of our disciplines is also essential. Fortunately, such collaboration has become more frequent in the last few years.

To us, what lies ahead is a wide-open research agenda. In this lecture, we suggested a possible approach, by deriving testable predictions from some simple theoretical models. Even though the empirical results we presented are preliminary, 
we think they are encouraging enough to proceed. We hope to have convinced other economists that more research on comparative politics is both worthwhile and exciting. 


\section{References}

Alesina, A., Easterly, W., Baqir, R., 1997. Public goods and ethnic divisions. NBER working paper no. 6009.

Alesina, A., Perotti, R., 1996. Budget deficits and budget institutions. NBER working paper no. 5556 .

Baron, D., 1997. Comparative dynamics of parliamentary government. Mimeo, Graduate School of Business, Stanford University.

Barro, R., 1973. The control of politicians: An economic model, Public Choice 14, 19-42.

Bingham Powell Jr., G. 1982. Contemporary Democracies: Participation, Stability, and Violence. Harvard University Press, Cambridge MA.

Cameron, D.R. 1978., The expansion of the public economy: A comparative analysis. American Political Science Review 72, 1203-61.

Coughlin, P, Nitzan, S., 1981. Electoral outcomes with probabilistic voting and Nash social welfare maxima. Journal of Public Economics 15, 113-121.

Cox, G. W., 1997. Making Votes Count: Strategic Coordination in the World's Electoral Systems. Cambridge University Press, New York.

Diermeier, D., Feddersen, T., 1998. Cohesion in legislatures and the vote of confidence procedure. American Political Science Review 92.

Easterly, W., Levine, R., 1997. Africa's growth tragedy: policies and ethnic divisions. Quarterly Journal of Economics 112, 1203-50.

Ferejohn, J., 1986. Incumbent performance and electoral control. Public Choice 50, 5-26.

Frey, B.S., 1983. Democratic Economic Policy: A Theoretical Introduction. Basil Blackwell, Oxford.

Gastil, R., 1987. Freedom in the World: Political Rights and Civil Liberties 1986/1987. Freedom House, New York.

Goode, R., 1984. Government Finance in Developing Countries. The Brookings Institution, Washington, D.C.

Grilli, V., Masciandaro, D., Tabellini, G., 1991. Political and monetary institutions and public financial policies in the industrialized countries. Economic Policy 13.

Grillo, M., Polo, M., 1993. Political exchange and allocation of surplus: A model of two-party competition. In Breton A., Galeotti G., Salmon P., Wintrobe R. (eds.), Preferences and Democracy, Kluwer Academic Publishers, Norwell, MA.

Hinich, M.J., Ledyard, J.O., Ordershook, P. C., 1972. Nonvoting and the 
existence of equilibrium under majority vote. Journal of Economic Theory 44, 144-153.

Inter-American Development Bank, 1997. Economic and social progress report 1997. Part III.

Inman, R.P., Rubinfeld, D.L., 1997. The political economy of federalism. In: Mueller, D.C.(ed.) Perspectives On Public Choice: A Handbook. Cambridge University Press, New York.

Lijphart, A., 1984. Democracies: Patterns of Majoritarian and Consensus Government in Twenty-One Countries. Yale University Press, New Haven, Conn.

Lindbeck, A.,Weibull, J., 1987. Balanced-budget redistribution as the outcome of political competition. Public Choice 52, 273-97.

Lindert, P., 1996. What limits social spending? Explorations in Economic History 33, 1-34.

Lizzeri, A., Persico, N., 1998. The provision of public goods under alternative electoral incentives. Mimeo, University of Toulouse.

Mauro, P., 1998. Corruption and the composition of government expenditure. Journal of Public Economics 69, 263-80.

Mueller, D.C., 1989. Public Choice II. A Revised Edition of Public Choice. Cambridge University Press, New York.

Mueller, D.C. (ed.), 1997. Perspectives on Public Choice: A Handbook. Cambridge University Press, New York.

Myerson, R., 1993. Effectiveness of electoral systems for reducing government corruption: A game theoretic analysis. Games and Economic Behavior 5, 118-32.

Myerson, R., 1998. Theoretical comparison of electoral systems: 1998 Schumpeter lecture. Berlin Congress of the European Economic Association.

Panizza, U., 1997. On the determinants of fiscal centralization: theory and evidence. Mimeo, Department of Economics, University of Turin.

Persson, T., Tabellini, G., 1998. Political economics and public finance. Forthcoming in: Auerbach, A., Feldstein, M. (eds.) Handbook of Public Economics, North Holland.

Persson, T., Roland, G., Tabellini, G., 1997. Separation of powers and political accountability. Quarterly Journal of Economics 112, 1163-1202.

Persson, T., Roland, G., Tabellini, G., 1998a. Comparative politics and public finance. IGIER working paper no. 114.

Persson, T., Roland, G., Tabellini, G., 1998b. Towards micropolitical foundations of public finance. European Economic Review 42, 685-694.

Polo, M., 1998. Electoral competition and political rents. Mimeo, IGIER. 
Pommerehne, W. W., Frey, B. S., 1978. Bureaucratic behaviour in democracy: a case study. Public Finance 33, 98-112.

Rodrik, D., 1998. Why do more open economies have bigger goverments? NBER working paper no. 5537. Cambridge, MA.

Roubini, N., Sachs, J., 1989. Political and economic determinants of budget deficits in the industrial democracies. European Economic Review 33, 903-933.

Shugart, M.S., Carey, J. M., 1992. Presidents and Assemblies: Constitutional Design and Electoral Dynamics. Cambridge University Press, New York.

Stigler, G., 1972. Economic performance and political competition. Public Choice 13, 91-106.

Strömberg, D., 1998. Radio's impact on New Deal spending. Mimeo, Institute for International Economic Studies, Stockholm.

Svensson, J., 1997. The control of public policy: Electoral competition, polarization and primary elections. Mimeo, The World Bank, Washington, D.C.

Taagepera, R., Shugart, M.S., 1989. Seats \& Votes. The Effects and Determinants of Electoral Systems. Yale University Press, New Haven, Conn.

Von Hagen, J., Harden, I., 1996. Budget processes and commitment to fiscal discipline. IMF working paper.

White, H., 1980. A heteroskedasticity-consistent covariance matrix estimator and a direct test for heteroskedasticity. Econometrica 48, 817-38.

Wittman, D., 1989. Why democracies produce efficient results. Journal of Political Economy 97, 1395-424. 


\section{Graph 1}

\section{Size of Government}

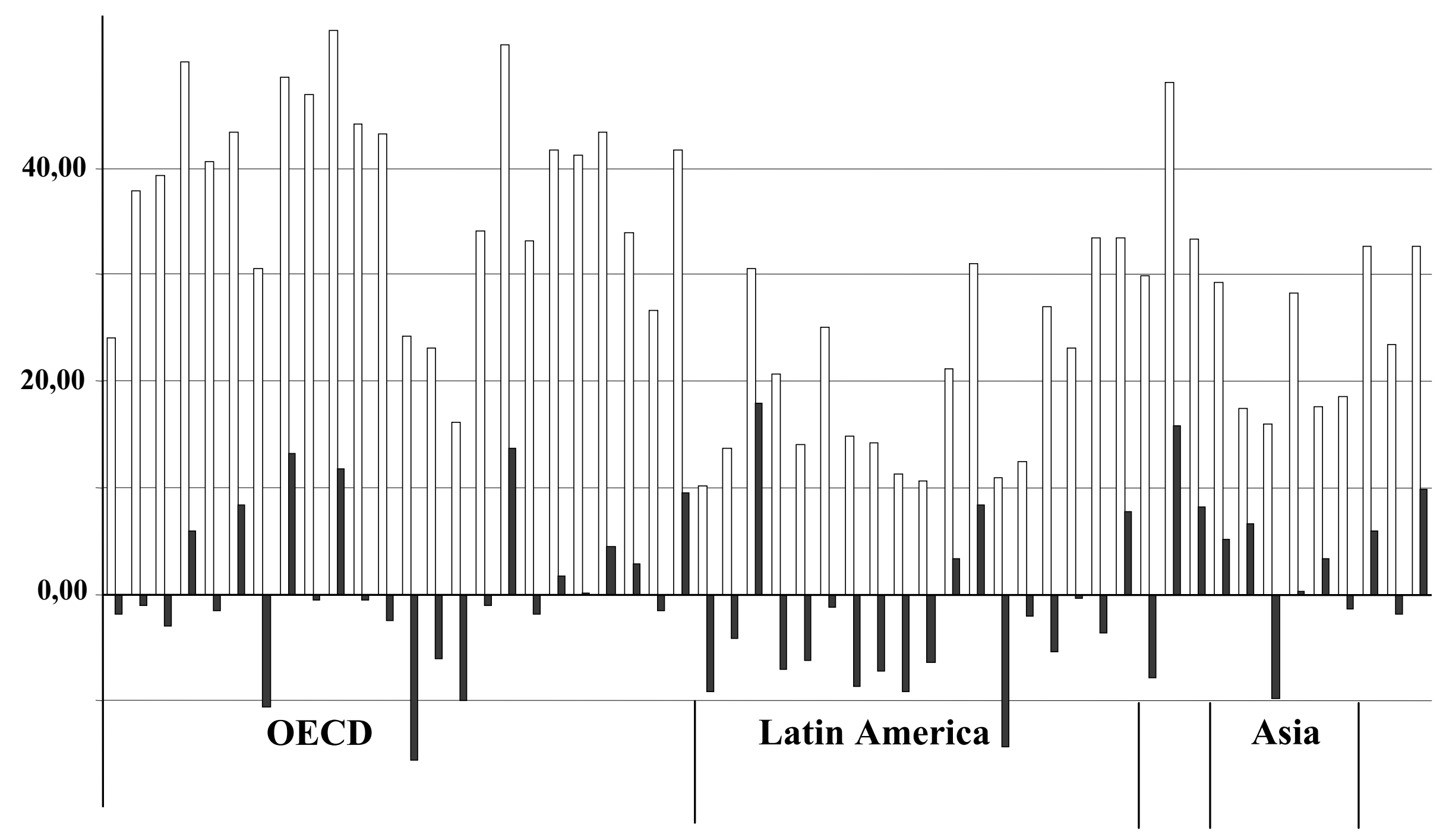


Graph 2

Public Goods

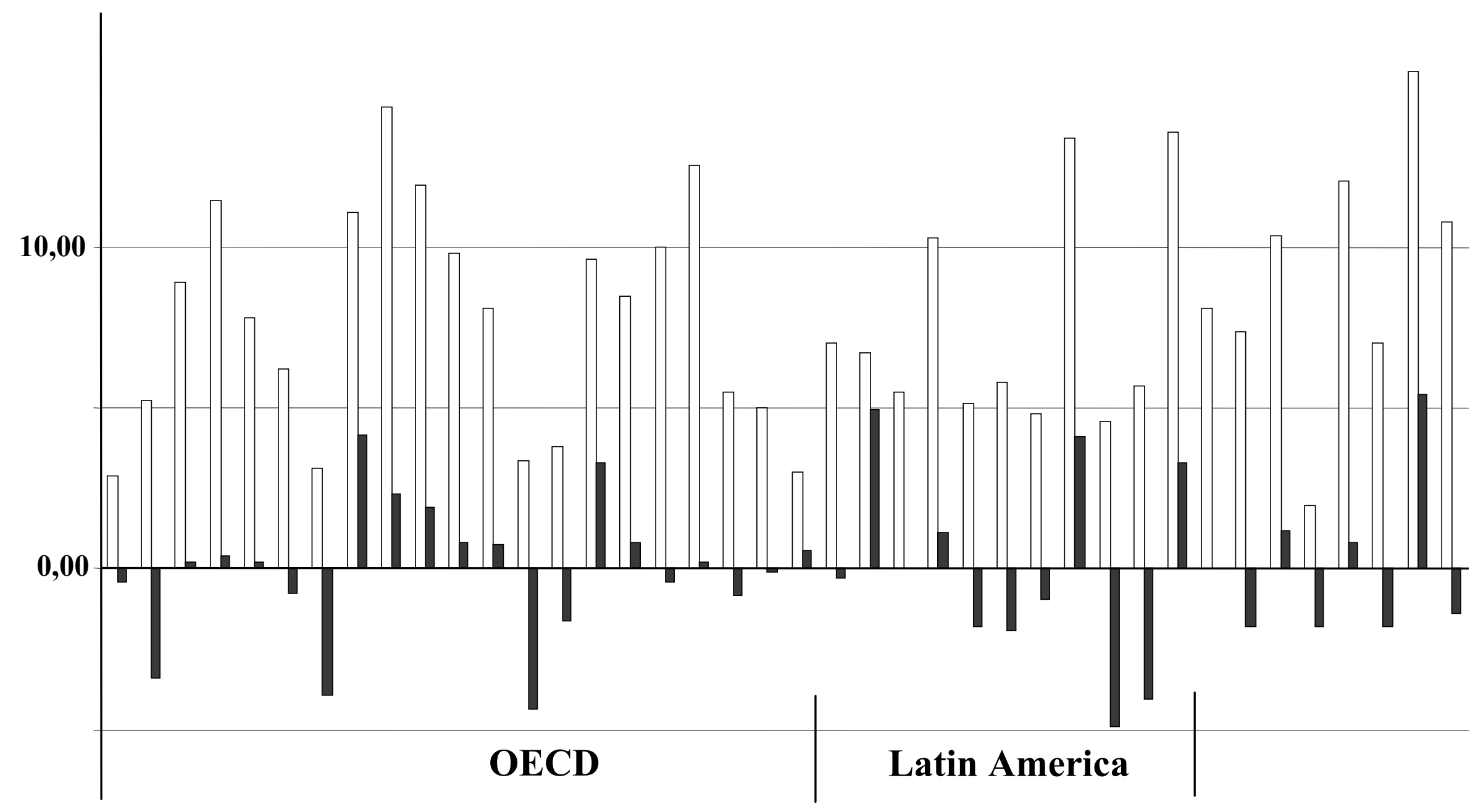


Figure 1

Distributions of voters' ideological preferences

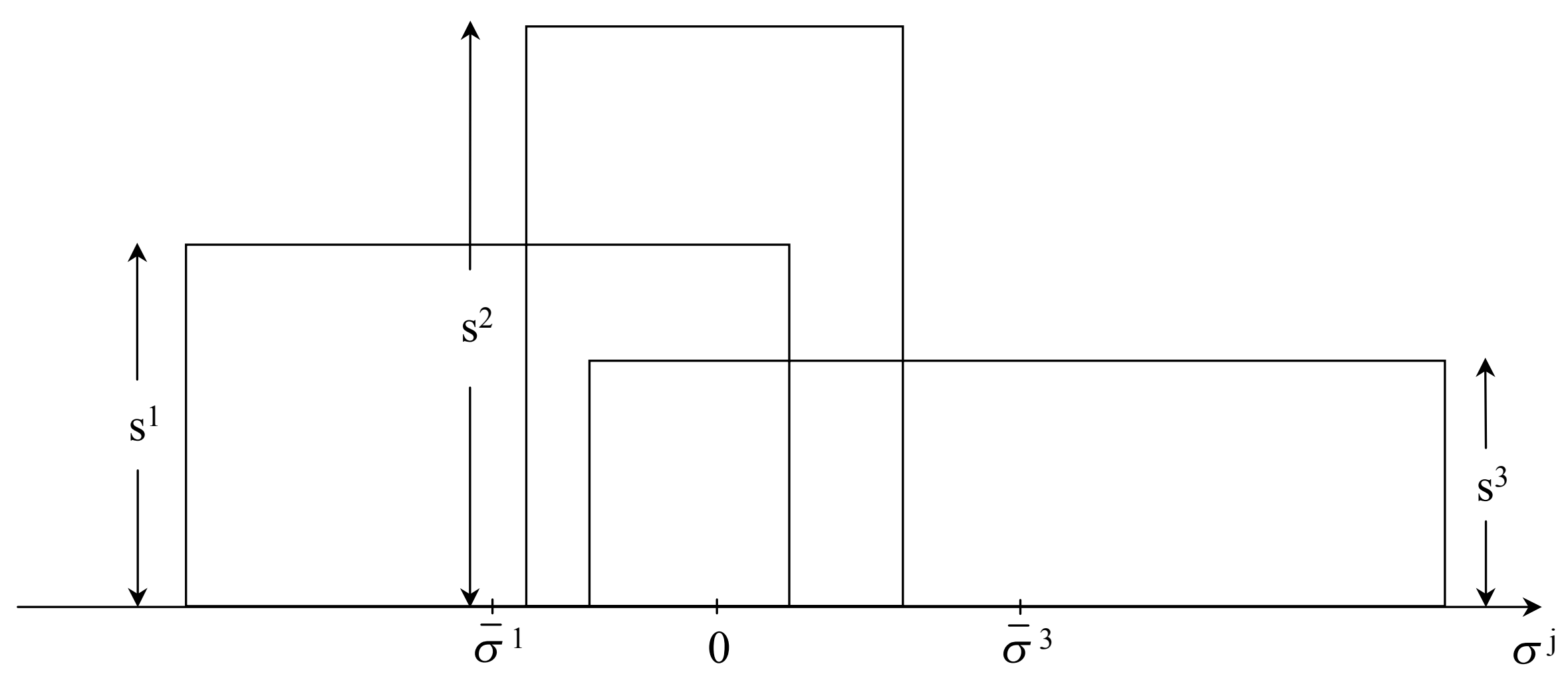




\section{Figure 2 \\ Distributions of preferences in marginal district}

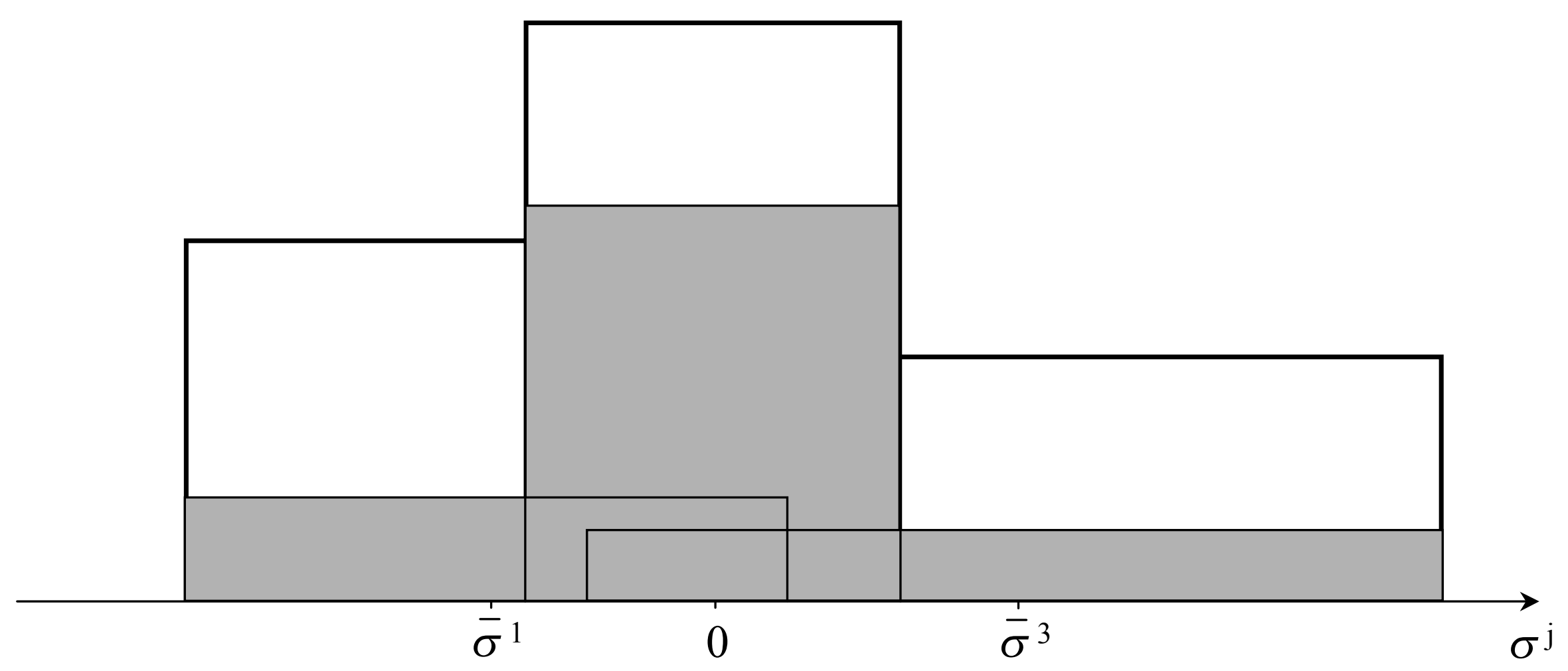




\section{Figure 3 \\ Presidential regime}

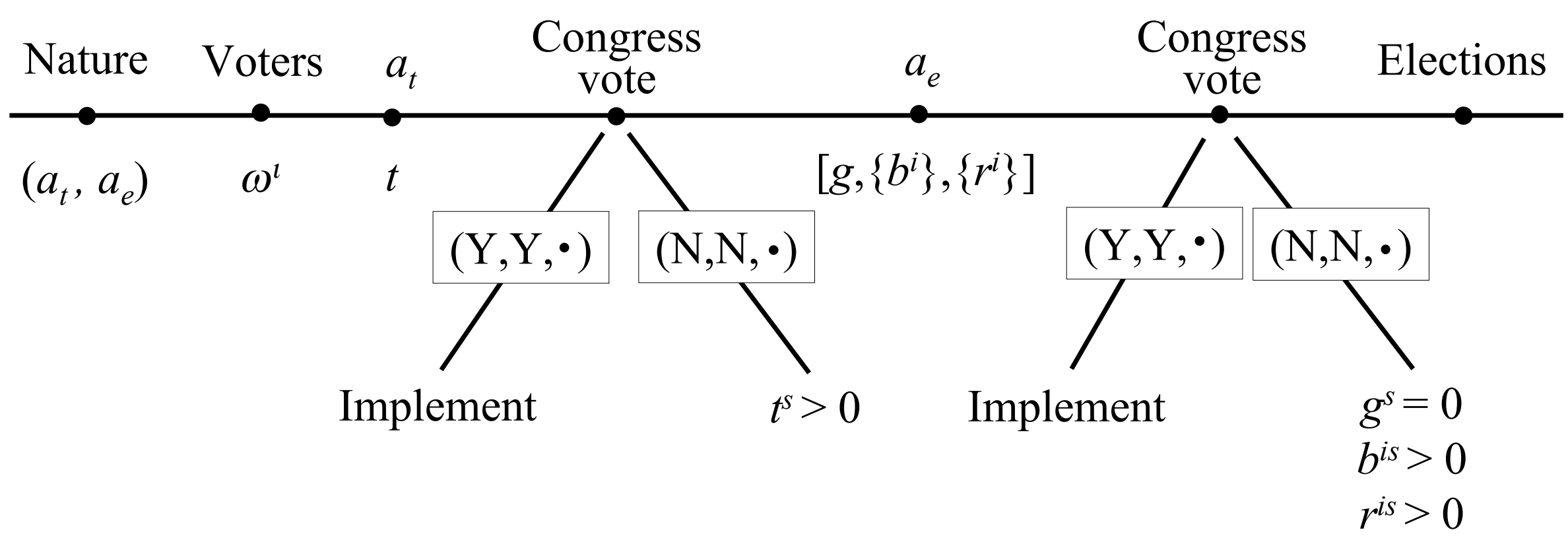

$a_{t} \equiv$ agenda setter for taxes

$a_{e} \equiv$ agenda setter for expenditures

Congress $\equiv\left(a_{t}, a_{e}, \bullet\right)$ 


\section{Figure 4 \\ Parliamentary regime}

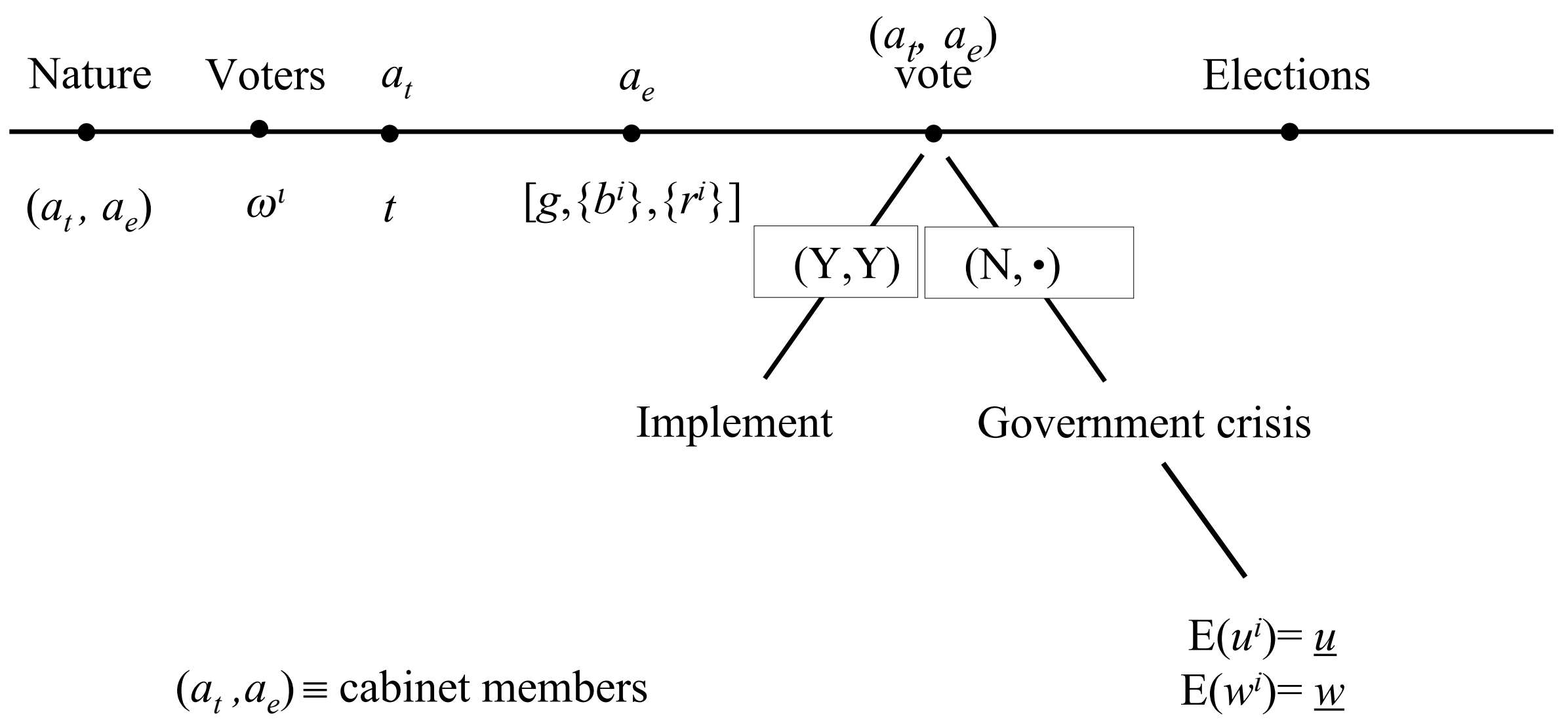




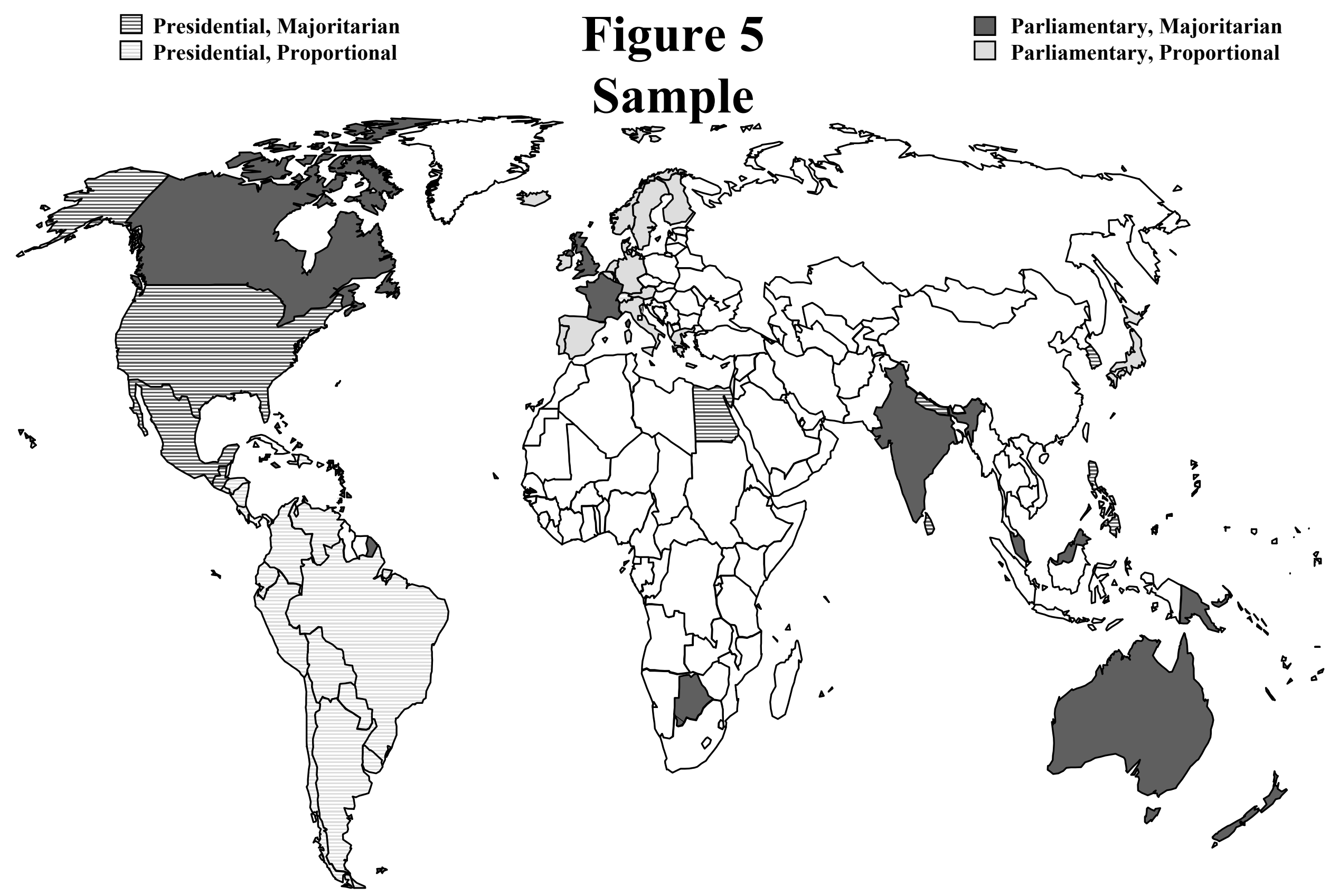




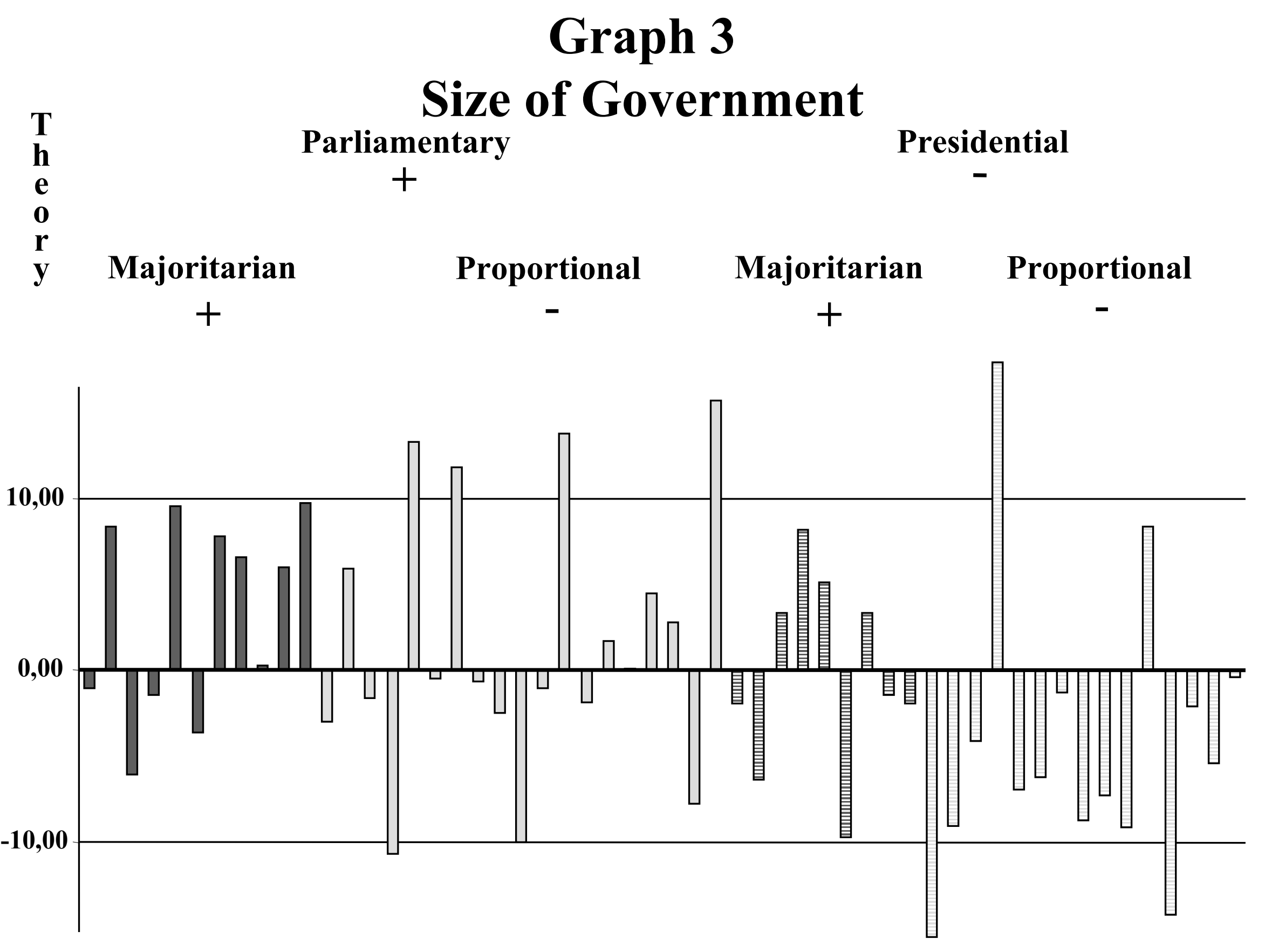




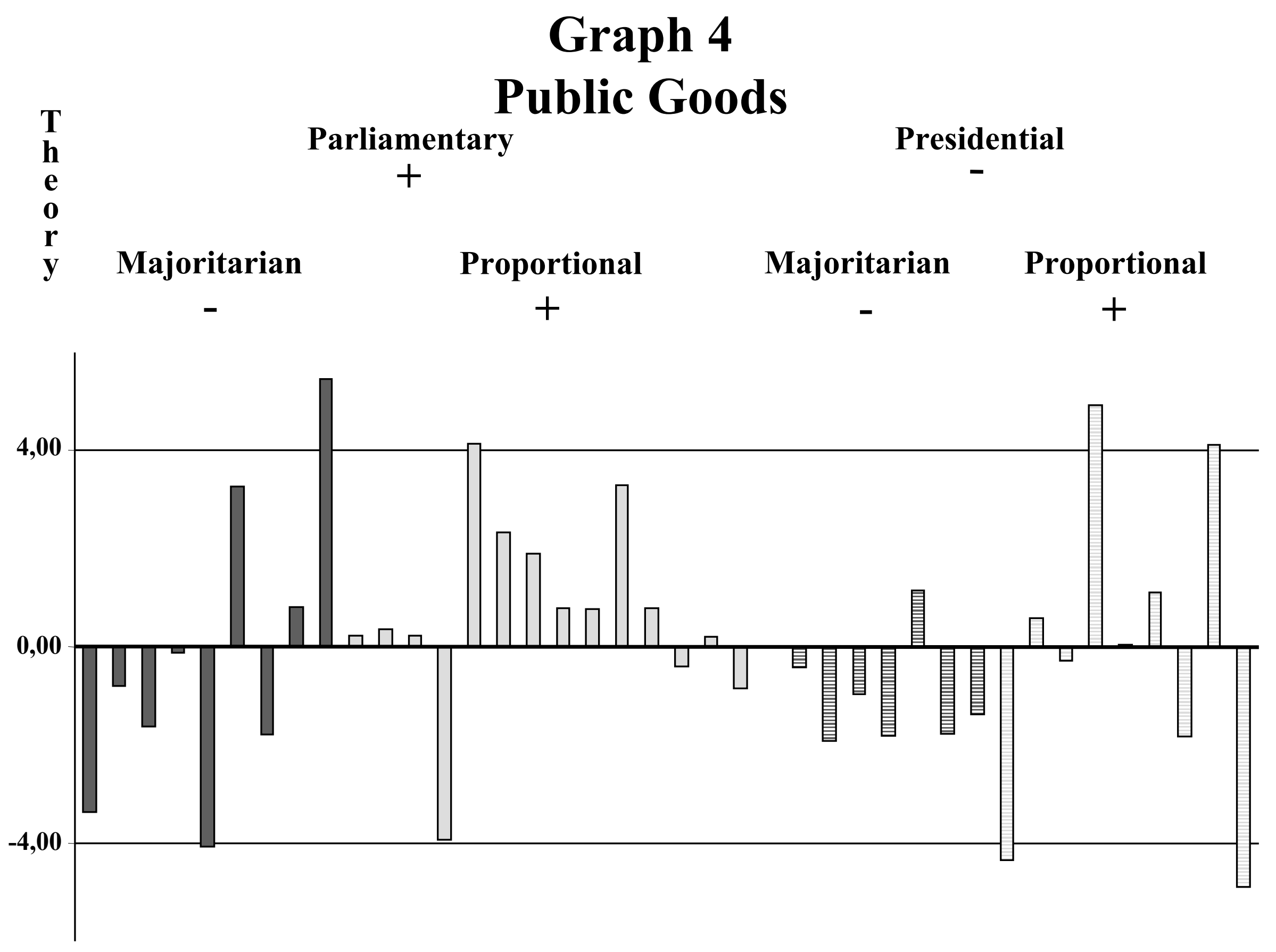


Table 1 Central Govt.
Size of:

General Govt.

\begin{tabular}{|c|c|c|c|c|c|c|c|}
\hline Controls: & $\mathrm{X}^{\mathrm{B}}$ & $X^{B}$ & $\mathrm{X}^{\mathrm{B}}$ & $X^{E}$ & $X^{B}, C$ & $X^{B}$ & $X^{B}$ \\
\hline PRES & $\begin{array}{r}-10.00 \\
(-4.60)\end{array}$ & & & $\begin{array}{l}-8.87 \\
(-4.40)\end{array}$ & $\begin{array}{c}-8.43 \\
(-3.82)\end{array}$ & $\begin{array}{l}-11.80 \\
(-4.26)\end{array}$ & \\
\hline MAJ & & $\begin{array}{c}4.14 \\
(1.71)\end{array}$ & & & & & \\
\hline MAJPRES & & & $\begin{array}{c}-7.46 \\
(-1.89)\end{array}$ & & & & $\begin{array}{l}-14.29 \\
(-2.68)\end{array}$ \\
\hline PROPRES & & & $\begin{array}{l}-11.99 \\
(-3.49)\end{array}$ & & & & $\begin{array}{l}-15.16 \\
(-3.54)\end{array}$ \\
\hline MAJPARL & & & $\begin{array}{c}-0.41 \\
(-0.13)\end{array}$ & & & & $\begin{array}{l}-5.12 \\
(-1.26)\end{array}$ \\
\hline \# Obs. & 54 & 54 & 54 & 43 & 54 & 40 & 40 \\
\hline$\overline{\mathbf{R}}^{2}$ & 0.66 & 0.59 & 0.66 & 0.71 & 0.65 & 0.64 & 0.63 \\
\hline
\end{tabular}

$t$ - ratios in parentheses, corrected for heteroscedasticity 


\section{Table 2}

Public goods: Basic

\section{Broad}

\begin{tabular}{|c|c|c|c|c|c|c|c|}
\hline Controls: & $Z^{B}$ & $Z^{B}$ & $Z^{B}$ & $Z^{B}$ & $Z^{E}$ & $Z^{B}, C$ & $Z^{B}$ \\
\hline PRES & $\begin{array}{c}-1.60 \\
(-1.27)\end{array}$ & & & & & & \\
\hline MAJ & & $\begin{array}{c}-1.17 \\
(-1.26)\end{array}$ & & & $\begin{array}{c}0.16 \\
(0.16)\end{array}$ & $\begin{array}{l}-2.28 \\
(-1.98)\end{array}$ & $\begin{array}{l}-1.83 \\
(-1.33)\end{array}$ \\
\hline
\end{tabular}

MAJPRES

$-3.74$

$(-2.79)$

PROPRES

$-2.55$

$(-1.81)$

MAJPARL

$-1.95$

$(-1.69)$

MAJORIT

$-1.40$

$(-1.10)$

\begin{tabular}{lccccccc}
\hline \# Obs. & 40 & 40 & 40 & 35 & 39 & 40 & 40 \\
$\overline{\mathbf{R}}^{2}$ & 0.48 & 0.47 & 0.49 & 0.46 & 0.54 & 0.49 & 0.35
\end{tabular}

$\mathrm{t}$ - ratios in parentheses, corrected for heteroscedasticity 